Author copy of the final (peer-reviewed) version of the article published in Tectonophysics in April 2021 in: Deformation processes in the ductile crust and mantle, seismic anisotropy, ocean ridge dynamics: A special issue in honor of Adolphe Nicolas; Edited by: A.Vauchez, A.Tommasi, S.Ji, J.Koepke, K.Michibayashi, J.A.Padron-Navarta

Please, reference to: Wang, X., Zhang, J., Tommasi, A., Jing, Z., Yuan, M. Microstructure and seismic properties of amphibole-rich rocks from southern Tibet. Tectonophysics, 811: 228869, doi: 10.1016/j.tecto.2021.228869

\title{
Microstructure and seismic properties of amphibole-rich rocks from the deep crust in southern Tibet
}

\author{
Xiong Wang ${ }^{\mathrm{a}, \mathrm{b}}$, Junfeng Zhang ${ }^{\mathrm{a}, *}$, Andréa Tommasi ${ }^{\mathrm{c}, *}$, Zhicheng Jing ${ }^{\mathrm{b}}$, Maoshan Yuan ${ }^{\mathrm{b}}$ \\ ${ }^{\text {a }}$ State Key Laboratory of Geological Process and Mineral Resources, School of Earth Sciences, China University of Geoscience, 430074 Wuhan, China \\ ${ }^{\mathrm{b}}$ Department of Earth and Space Sciences, Southern University of Science and Technology, 518055 Shenzhen, China \\ ${ }^{\mathrm{c}}$ Géosciences Montpellier, CNRS \& Université de Montpellier, 34095 Montpellier, France
}

A R T I C L E I N F O

\section{Keywords:}

Seismic anisotropy

Amphibole

CPOs

Deep crust

Southern Tibet

\begin{abstract}
A B S T R A C T
The crust of southern Tibet shows strong azimuthal and radial seismic anisotropies. However, their origin has remained ambiguous. Here we characterized the composition, microstructure, and seismic properties of amphibole-rich deep-crust xenoliths and exhumed rocks from a deep-crust terrane in southern Tibet. The xenoliths show typical magmatic textures and have amphiboles with homogenous chemical composition, low intracrystalline deformation, but strong crystallographic preferred orientations (CPOs). We interpret these CPOs as products of rotation of non-equant amphibole crystals in a deforming magma. The exhumed amphibolites display evidence for amphibole deformation by dislocation creep. Plagioclase in all samples shows nearly random CPOs. The calculated seismic properties of the studied amphibolites indicate that amphibole is likely a major contributor to the deep-crustal seismic anisotropies observed in southern Tibet. However, these anisotropies do not necessarily record solid-state flow. They may also result from magmatic flow in large synkinematic mafic plutons.
\end{abstract}

\section{Introduction}

Seismic anisotropy is a powerful tool to decipher the deformation patterns in the deep Earth. Geophysical observations show that seismic anisotropy is ubiquitous in the lithosphere, asthenosphere, and lowermost mantle (D") (Ferreira et al., 2019; Wookey et al., 2002; Wu et al., 2015). Seismic anisotropy is commonly ascribed to crystallographic preferred orientations (CPOs) of mica (Lloyd et al., 2009) and amphibole (Tatham et al., 2008) in the deep crust, olivine (Nicolas and Christensen, 1987) in the upper mantle, wadsleyite (Kawazoe et al., 2013; Tommasi, 2004) in the mantle transition zone, post-perovskite in the $\mathrm{D}^{\prime \prime}$ layer (Merkel et al., 2007; Tommasi et al., 2018; Wu et al., 2017). The basic principle behind the interpretation of deformation patterns from seismic anisotropy data is to be able to link the anisotropies in seismic velocities to CPOs of major rock-forming minerals and the CPOs to a deformation geometry. Thus, we can infer the deformation patterns from seismic anisotropy data if the process producing the CPOs is well known, as in dislocation creep. However, a large body of evidence indicates that strong CPOs can also be produced by other mechanisms, for instance, cataclastic flow (Ko and Jung, 2015), anisotropic growth during diffusion creep (Getsinger and Hirth, 2014; Miyazaki et al., 2013), oriented crystallization in a rock deforming in the presence of fluids (Imon et al., 2004; Stokes et al., 2012; Giuntoli et al., 2018) or melt topotactic reactions (Boudier et al., 2010; Higgie and Tommasi, 2012; Padrón-Navarta et al., 2008; Tommasi et al., 2017), and crystal rotations and interactions during magmatic flow (Berger and Stünitz, 1996; Ildefonse et al., 1992; Nicolas, 1992). However, in these cases, the rules linking the CPO-induced seismic anisotropies to the deformation patterns may differ from those for CPOs produced by dislocation creep. The determination of processes responsible for the development of CPOs is, therefore, an essential step for the interpretation of seismic anisotropy data, especially in tectonic settings with abundant magmatic activities, such as orogenic belts.

The $P$ to $S$ converted phase from the Moho $(P m S)$ permits the characterization of the azimuthal anisotropy in the crust (Liu and Niu, 2012). Strong shear wave anisotropy, quantified by the polarization orientation of the fast shear wave $(\phi)$ and the delay time $(\delta t)$ between the fast and slow shear waves, is observed in the crust of southern Tibet (Fig. 1a). The fast shear wave polarization directions are mainly subparallel to the India-Asia suture boundary. The average shear wave delay times are $0.50 \pm 0.15 \mathrm{~s}$ in central Tibet (Wu et al., 2019), $0.50 \pm 0.40 \mathrm{~s}$ in east Tibet (Sun et al., 2015), and $0.48 \pm 0.13 \mathrm{~s}$ in southeastern Tibet (Cai

\footnotetext{
* Corresponding authors.

E-mail addresses: jfzhang@cug.edu.cn, jf_zhang98@yahoo.com (J. Zhang), andrea.tommasi@umontpellier.fr (A. Tommasi).
} 
et al., 2016; Kong et al., 2016; Sun et al., 2012; Zheng et al., 2018). In southwestern Tibet, fast polarizations are at a high angle to the suture and delay times more variable, ranging between 0.45 and $1.3 \mathrm{~s}$ (Wu et al., 2015). Strong radial anisotropy is also observed using surface waves in the deep crust (peak of sensitivity at $35 \mathrm{~km}$ ) of southeastern Tibet (Fig. 1b) (Hu et al., 2020). These studies propose that the observed crustal anisotropy mainly originates from CPOs formed during ductile deformation of the middle-lower crust (Agius and Lebedev, 2017; Chen et al., 2016; Shapiro et al., 2004). Amphibole, because of its abundance in the deep crust and high intrinsic seismic anisotropies, has often been proposed to explain strong crustal anisotropies (Ko and Jung, 2015; Li et al., 2020; Tatham et al., 2008). However, observations of naturally and experimentally deformed amphibolites show that most of the processes cited above may produce strong amphibole CPOs (Elyaszadeh et al., 2018; Getsinger and Hirth, 2014; Imon et al., 2004; Ko and Jung, 2015; Skrotzki, 1992; Stokes et al., 2012; Tommasi et al., 2017). Determination of the processes producing amphibole CPOs in the deep crust of Tibet is therefore important for the interpretation of the seismic anisotropy data.

In southern Tibet, the deep crust underwent a series of deformation, metamorphic and magmatic events during subduction and collision (Zhu et al., 2015). Deep crustal amphibolite xenoliths carried by mantlederived magmas usually display strong amphibole CPOs (Ji et al., 2015), but the processes responsible for these CPOs have not been constrained. Due to fluid release during subduction, amphibole-rich rocks may form by hydration reactions in the deep crust. In such a setting, amphibole CPOs may form by either oriented or topotactic growth. Fractional crystallization of hydrous basaltic magma may also produce amphibolerich cumulates (Davidson et al., 2007; Zhou et al., 2020). Due to the strongly anisometric crystal shape of amphiboles, CPOs of amphibole may form during the crystallization of these magmas. These CPOs will show a large-scale ( $\mathrm{km}$ to tens of $\mathrm{km}$ ) organization if the magmatic flow is controlled by a large-scale (tectonic) stress field, as observed in synkinematic plutons (e.g., Nicolas, 1992; Vauchez et al., 2019).

To further constrain the processes responsible for the observed seismic anisotropies in the middle-lower crust of southern Tibet, we have characterized the compositions, microstructures, CPOs, and seismic properties of amphibole-rich deep-crust xenoliths and exhumed rocks from a deep-crust terrane in southern Tibet.

\section{Geological setting and samples}

The Tibetan-Himalayan orogenic system formed by collision between the Indian and Asian continents during the Cenozoic (Yin and Harrison, 2000). The Tibetan Plateau is composed of, from south to north, the Himalaya, Lhasa, Qiangtang, and Songpan-Ganzi terranes (Fig. 1a). The Lhasa terrane lies between the Bangong-Nujiang suture zone in the north and the Indus-Tsango suture zone (ITS) in the south. It can be divided into northern, central, and southern subterranes based on different sedimentary cover rocks (Zhu et al., 2015). The southern Lhasa subterrane hosts the widespread Cretaceous-early Tertiary Gangdese batholith and the Linzizong volcanic succession (Zhu et al., 2015). Three amphibole-rich rocks (\#521, \#431-1, and \#431-2) were collected from enclaves in granitic gneisses of the Gangdese batholith (Fig. S1c-d and see locations in Fig. 1b). Isotopic data indicated these xenoliths may represent cumulates or residuals of basaltic magma ponding at the base of crust (Xu et al., 2019).

The Eastern Himalayan Syntaxis (EHS), located at the eastern part of Himalayan orogen (black box in Fig. 1b), is a strongly deformed and fast exhumed terrane subjected to migmatitization (Booth et al., 2009). The EHS includes three major tectonic units: the Lhasa terrane, representing the southern segment of the Asian continent; the ITS, forming the residual of the Neo-Tethyan Ocean between the Asian and Indian plates; and the Himalayan sequences, representing the northern margin of the Indian continent (Yin and Harrison, 2000). The Higher Himalayan Crystalline (HHC) unit, locally referred to as the Namche Barwa Complex (NBC), mainly consists of high-grade gneiss, amphibolite, schist, marble, granulite, and migmatite, and is interpreted as an exhumed middle-lower crust, which has been subjected to extensive partial melting (Kang et al., 2020). Amphibolite occurs interlayered with schist and gneiss and usually shows clear deformation structures (foliation and lineation). A recent study showed that the protoliths of these amphibolites were mafic magmatic rocks of Late Paleoproterozoic age (Kang et al., 2020) and that the amphibolites recorded a clockwise $P$ - $T$ path with peak metamorphism of high-pressure granulite-facies, leading to extensive partial melting associated with amphibole dehydration under conditions of $1.6-1.8 \mathrm{GPa}$ and $<800{ }^{\circ} \mathrm{C}$ at $40-20 \mathrm{Myr}$, followed by retrogression to $0.5-0.6 \pm 0.1 \mathrm{GPa}$ and $695-740 \pm 35^{\circ} \mathrm{C}$ between 20 and $10 \mathrm{Myr}$ (Kang et al., 2020). Three amphibolite samples (16lzwx1-3) were collected from a thick layer of amphibolite in the core of the EHS (see locations in Fig. 1b).
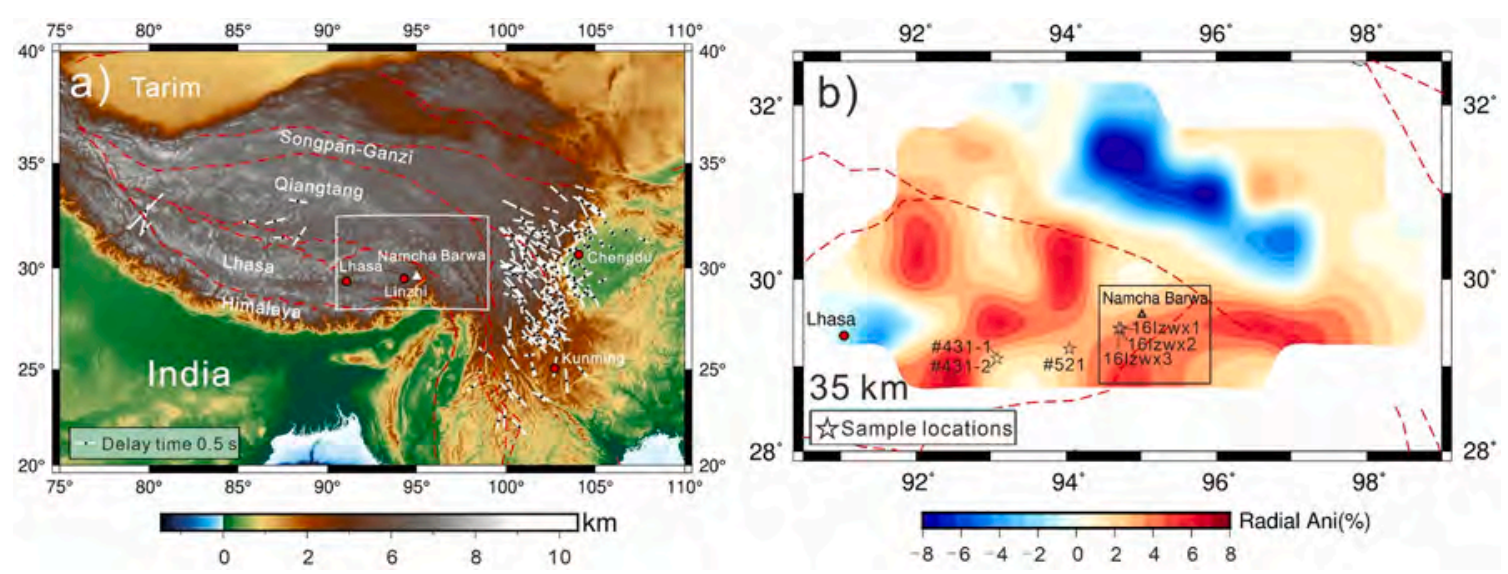

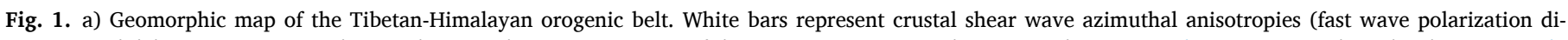

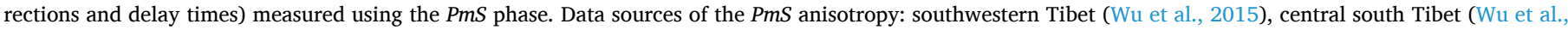

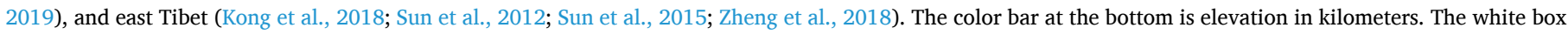

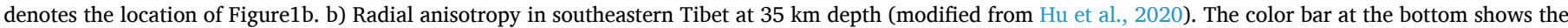

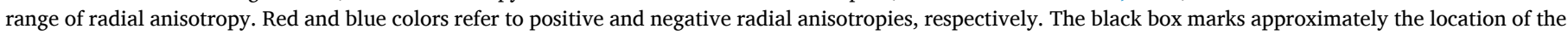

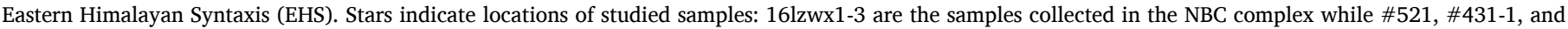

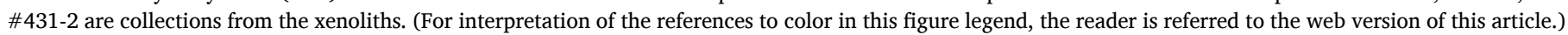




\section{Methods}

The foliation and lineation of exhumed samples from EHS were determined based on the shape preferred orientation (SPO) of amphibole grains and field observations; thin sections were prepared normal to foliation and parallel to the lineation. Thin sections for xenoliths \#431-1 and \#431-2 were cut in a random direction normal to the compositional layering, as the lineation could not be determined. Xenolith \#521 was cut randomly because it is composed of nearly pure amphibole and no SPO can be determined. All thin sections were polished until the sample surfaces were even and clean for microstructural and microprobe analyses. For EBSD mapping, vibration polishing with $0.05 \mu \mathrm{m}$ colloidal silica was applied for at least $4 \mathrm{~h}$ before measurements.

\subsection{Analysis of mineral compositions}

Quantitative compositional analyses of amphibole, plagioclase, and garnet were performed using a JEOL JXA-8230 electron probe microanalyzer at the Center for Global Tectonics, School of Earth Sciences, China University of Geosciences (Wuhan) with an accelerating voltage of $15 \mathrm{kV}$, a beam current of $20 \mathrm{nA}$, and a beam size of $1-3 \mu \mathrm{m}$. The following standards were used: Sanidine (K), Pyrope Garnet (Fe, Al), Diopside (Ca, Mg), Jadeite (Na), Rhodonite (Mn), Olivine (Si), Rutile (Ti) and Apatite (P).

\subsection{CPOs data acquisition and processing}

Crystal orientation data were obtained using a JEOL JSM 5600 scanning electron microscope equipped with EBSD system at Geosciences Montpellier, Université de Montpellier, France (Samples: 16lzwx1-3) and a Quanta 450 Field Emission Gun (FEG)-SEM-EBSD system at the School of Earth Sciences, China university of Geosciences, Wuhan (Samples: \#521, \#431-1, and \#431-2). Large area mapping of samples was performed to acquire a representative orientation dataset. Conditions during EBSD mapping were an accelerating voltage of $17 \mathrm{kV}$, a spot size of 5.5-6, and a working distance of $24 \mathrm{~mm}$. The automatic data were collected with a step size of $15-28 \mu \mathrm{m}$ depending on grain size. Raw indexing rates range between 78 and $85 \%$. The raw data have been noise-reduced using a "wild spike" correction with a threshold mean angular deviation (MAD) values of $1.3^{\circ}$. Non-indexed pixels with at least six neighboring coherent orientations have been filled with the average orientation of the neighbors using the CHANNEL 5 software.

The crystallographic data analyses were performed using the MTEX toolbox in MATLAB (Bachmann et al., 2010; Hielscher and Schaeben, 2008). CPOs data are displayed as one point per grain in pole figures presented as lower hemisphere stereographic projections. The CPOs data of sample \#521 was rotated by aligning the clusters of the [001] and [100] axes of amphibole parallel to lineation and normal to foliation of the other sample, respectively. Densities of pole figures were normalized to a uniform distribution. $J$-index (one point per grain) was used to quantify the strength of CPOs. The automatic grain detection routine in the MTEX toolbox (Bachmann et al., 2011) has been used for quantitative microstructure analyses. Grain boundaries are defined by misorientations between neighboring pixels $>10^{\circ}$. Grains composed by less than 10 pixels were not considered in the microstructural analysis (grain sizes and shapes). The misorientation of each pixel relative to the mean orientation of the grain (M2M) and the grain orientation spread (GOS) was calculated to quantify the intracrystalline orientation gradients, which is a proxy for dislocation density.

\subsection{Calculation of seismic properties}

The seismic properties of amphibole aggregates and amphibolite with varying amphibole/plagioclase ratios were computed using the MTEX tool (https://mtex-toolbox.github.io) with the measured CPOs data of constituent minerals, single-crystal elastic constants, the
Christoffel equation, and the Voigt-Reuss-Hill averaging scheme (Mainprice et al., 2011). The elastic constants $\left(C_{i j}\right)$ and densities $(\rho)$ of amphibole (Brown and Abramson, 2016) and plagioclase (Brown et al., 2016) used in the calculation of seismic properties were shown in Table S1. The parameters $\left(C_{i j}\right.$ and $\rho$ ) of $\mathrm{Ab}_{75} \mathrm{An}_{25}$ and $\mathrm{Ab}_{52} \mathrm{An}_{48}$ were used for plagioclase in samples 16lzwx2 and \#431-1 respecting the different chemical compositions of these samples.

\section{Results}

\subsection{Microstructures}

Photomicrographs and EBSD phase maps illustrating the microstructures of the six studied amphibolites are displayed in Figs. 2 and 3. The volume fractions of constituent minerals and microstructure parameters from EBSD mapping are presented in Table 1 . The amphibole content is $\geq 65 \mathrm{vol} \%$ in all samples. Other constituent minerals are plagioclase, garnet, quartz, and minor oxides.

The amphibolites (16lzwx1-3) from EHS are fresh samples from the cores of the lenticular amphibolites, which were only slightly affected by subsequent retrogression during exhumation. The amphibolite 16lzwx1 has a bimodal grain size distribution. It contains coarse-grained garnet and amphibole porphyroblasts enclosed in a medium-grained to finegrained matrix of amphibole and minor plagioclase and quartz (Fig. 3a). Coarse amphibole grains have lenticular shapes (Fig. 2a). The foliation, which is marked by the SPO of the amphibole, molds the garnet porphyroblasts (Fig. 2a). Minor fine-grained plagioclase (10\%) and quartz (1\%) are mainly located along grain boundaries of amphibole, locally forming patches flattened in the foliation plane (Figs. 2a, $3 a)$. The SPO of the coarse amphibole grains also marks a lineation.

The amphibolite 16lzwx2 is garnet-free and contains more plagioclase $(20 \%)$ and quartz (9\%) than sample 16lzwx1. Amphibole and plagioclase have similar mean grain sizes $(0.3-0.5 \mathrm{~mm})$ and, despite their irregular shapes, both show a strong SPO (maximum aspect ratio is presented in Table 1), which delineates the foliation and lineation (Figs. 2b, 3b). This sample also shows an incipient banding marked by alternating enrichment in amphibole or plagioclase (Fig. 3b). Quartz occurs mainly in flattened aggregates along amphibole grain boundaries.

The amphibolite 16lzwx 3 is composed of coarse garnet porphyroblasts $(5-8 \mathrm{~mm})$ enclosed in a medium-grained $(\sim 0.4 \mathrm{~mm})$ amphibole matrix (Fig. 3c). The garnet grains have nearly rounded shapes and are molded by the foliation formed by the amphibole SPO (Fig. 3c). Amphibole has subhedral to euhedral shapes and shows no evidence of intracrystalline deformation (Fig. 2c). Plagioclase and quartz form pressure-shadow structures around the garnet porphyroblasts, indicating retrogression during exhumation (Fig. 3c). Isolated small plagioclase and quartz grains can also be observed in the matrix.

The three amphibole-rich xenoliths have typical magmatic textures without evidence for either solid-state deformation or metamorphism (Fig. 2d and 3d-f). Sample \#521 is composed of nearly $100 \%$ coarsegrained amphibole $(\sim 1.7 \mathrm{~mm})$. It shows a very weak SPO (the trace of the foliation is roughly vertical in Fig. 3d). Sample \#431-1 has an equigranular texture. It is composed of amphibole (65\%), plagioclase (30\%), and minor quartz (3\%). Amphibole and plagioclase are coarsegrained (0.4-0.7 mm; Fig. 2d). Amphibole is subhedral to lens-shaped (Fig. 2d). Its SPO, together with the shape of the plagioclase aggregates, defines the foliation (Fig. 3e). Plagioclase grains have irregular shapes, but a weak SPO. They display well-developed polysynthetic growth twins (Fig. 2d). Variations in the amphibole and plagioclase proportions mark rough layering parallel to the foliation. Minor quartz occurs as isolated interstitial grains (Figs. 2d, 3e). It has a weak undulatory extinction (Fig. 2d). Sample \#431-2 has a higher amphibole content (76\%) and a lower plagioclase content (13\%) than sample \#4311. Amphibole has a weak SPO, marking a foliation (Fig. 3f). Both plagioclase and quartz occur as isolated grains in the amphibole matrix 

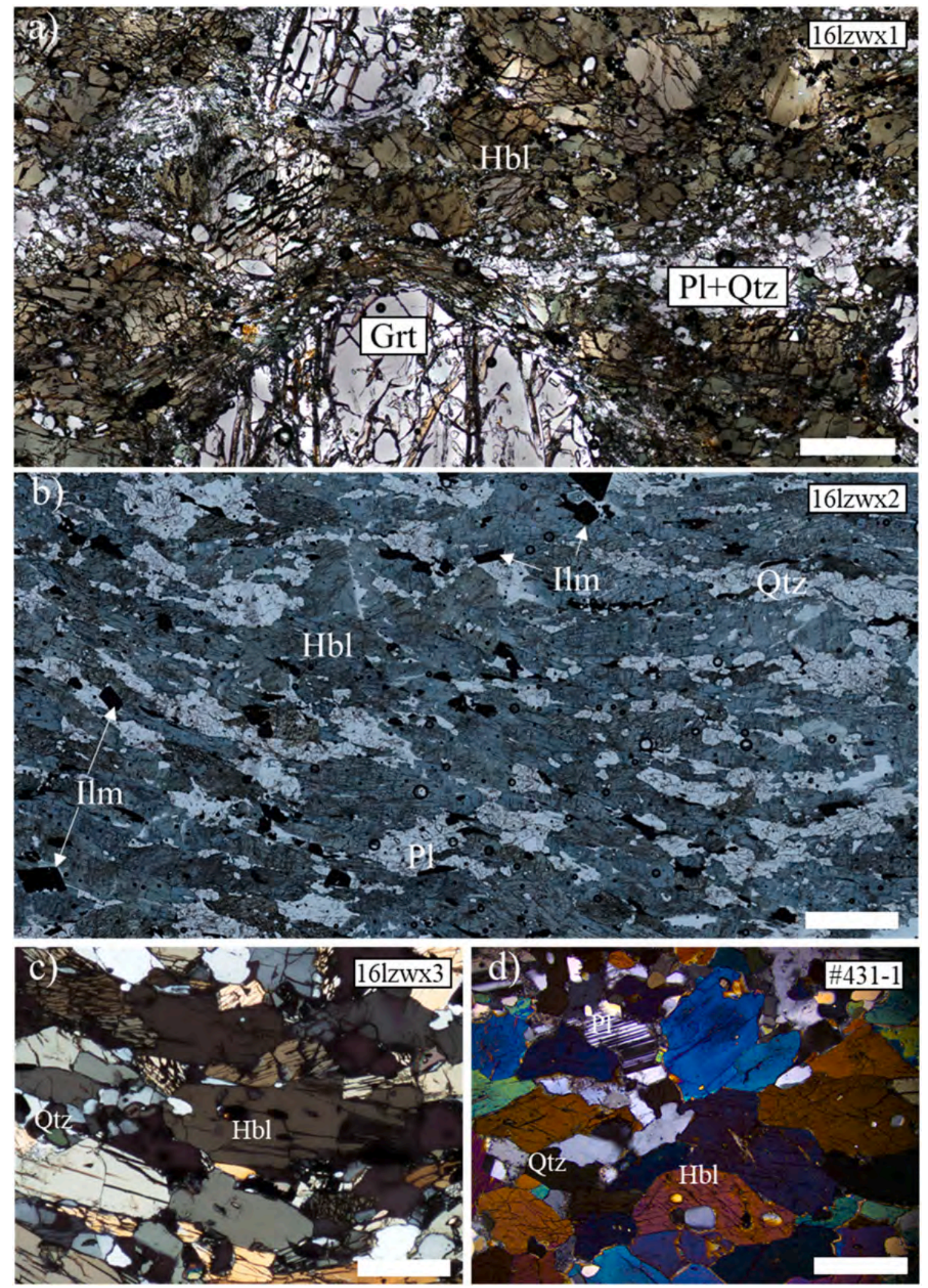

Fig. 2. Photomicrographs illustrating typical microstructures of amphibole-rich rocks from southern Tibet. a) Nearly round-shaped garnet (Grt) porphyroblasts enclosed in a matrix mainly composed of amphibole ( $\mathrm{Hbl}$ ) and minor fine-grained plagioclase ( $\mathrm{Pl}$ ) and quartz (Qtz). b) Distinct foliation defined by the amphibole SPO and the shapes of plagioclase aggregates. c) and d) Details of the microstructure illustrating the lack of evidence of intracrystalline deformation in both amphibole and plagioclase in sample 161zwx3 and the xenoliths. Minor quartz occurs as isolated irregularly shaped grains. In (d) plagioclase has polysynthetic twins and quartz has a weak undulatory extinction. (a-c) are plane-polarized light images and (d) is a cross-polarized light image. Ilm, ilmenite. Scale bars: a) $500 \mu \mathrm{m}$, b) $1000 \mu \mathrm{m}, \mathrm{c}) 300 \mu \mathrm{m}, \mathrm{d}) 400 \mu \mathrm{m}$. 

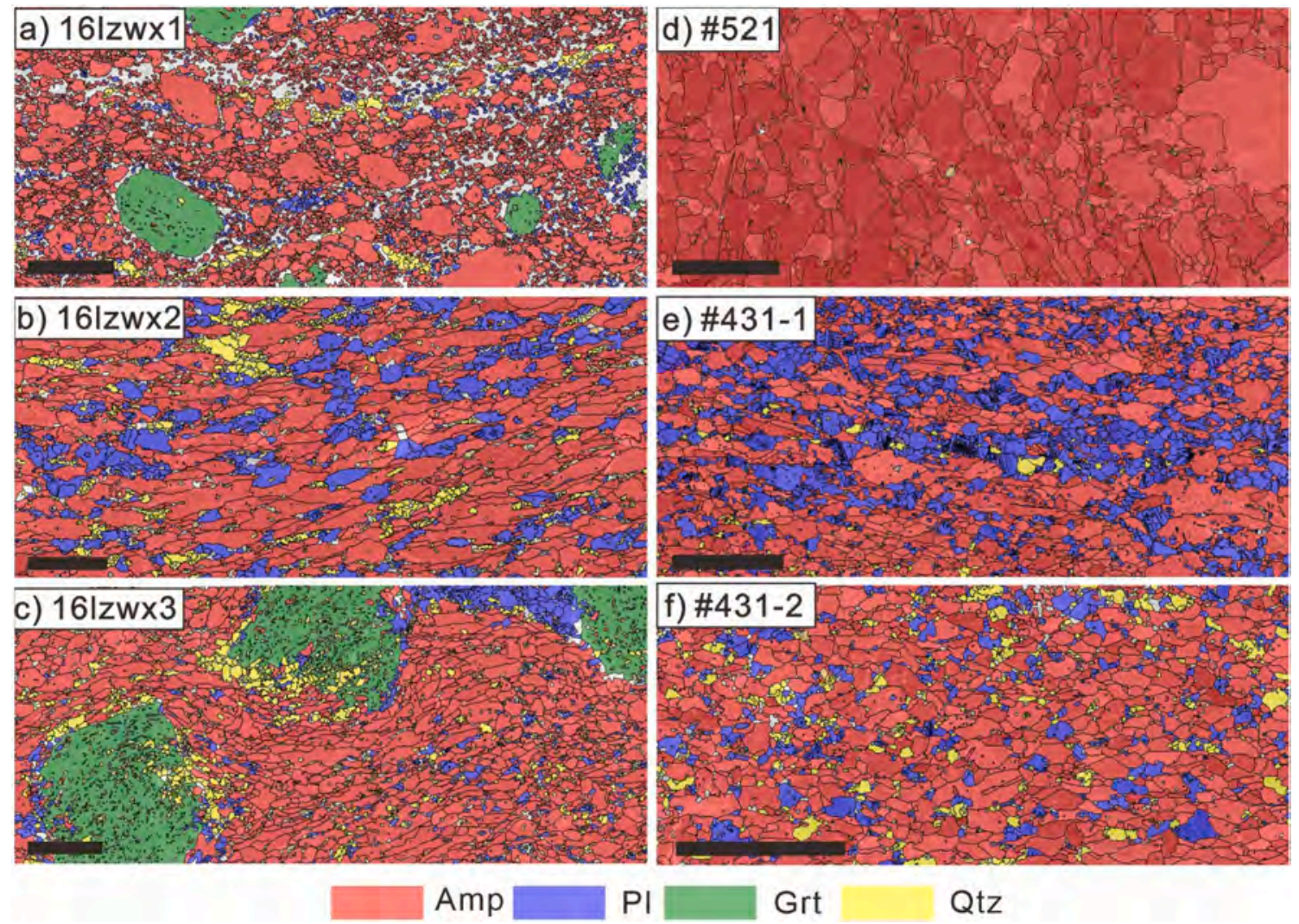

Fig. 3. EBSD phase maps of amphibole-rich rocks. Scale bars: $2 \mathrm{~mm}$ in (a, b, c) and $5 \mathrm{~mm}$ in (d, e, f).

Table 1

Modal composition and microstructure parameters derived from EBSD mapping.

\begin{tabular}{|c|c|c|c|c|c|c|c|c|c|c|c|c|c|}
\hline \multirow[t]{2}{*}{ Sample } & \multicolumn{4}{|c|}{ Modal composition (\%) } & \multirow{2}{*}{$\frac{\text { Index rate }}{(\%)}$} & \multicolumn{6}{|l|}{ Amp } & \multicolumn{2}{|l|}{$\mathrm{Pl}$} \\
\hline & Amp & $\mathrm{Pl}$ & Grt & Qtz & & Grain size $(\mu \mathrm{m})$ & Aspect ratio & Shape factor & $J$-ppg & M2M () & $\operatorname{GOS}\left(^{\circ}\right)$ & Grain size $(\mu \mathrm{m})$ & $J$-ppg \\
\hline 16lzwx1 & 77 & 10 & 8 & 1 & 85.8 & 365 & 1.6 & 1.8 & 1.9 & 2.45 & 1.52 & $53^{\mathrm{a}}$ & 1.3 \\
\hline 16lzwx2 & 69 & 20 & 0 & 9 & 79.8 & 556 & 3.0 & 2.2 & 5.4 & 1.63 & 1.15 & 311 & 2.2 \\
\hline \#521 & 100 & 0 & 0 & 0 & 86.5 & 1758 & 1.8 & 2.0 & 2.1 & 1.58 & 0.90 & - & - \\
\hline \#431-1 & 65 & 30 & 0 & 3 & 78.3 & 760 & 2.1 & 2.1 & 3.7 & 0.83 & 0.61 & 367 & 1.5 \\
\hline \#431-2 & 76 & 13 & 0 & 9 & 81.9 & 540 & 1.7 & 1.7 & 3.6 & 0.85 & 0.75 & 314 & 1.5 \\
\hline
\end{tabular}

Modal compositions were estimated as the area fraction occupied by each mineral on the EBSD maps, recalculated for a 100\% indexation.

Grain sizes (2D) were weighted (by the grain area) averages over the entire EBSD map.

$J$-ppg was calculated using the mean orientation of each grain.

${ }^{a}$ Plagioclase grain sizes of 16lzwx1 and 16lzwx3 are not reliable due to large step sizes (15 $\left.\mu \mathrm{m}\right)$ relative to fine grain size of plagioclase.

b Plagioclase $J$-ppg of 16 lzwx3 is probably overestimated due to the minor content of plagioclase in this sample.

(Fig. 3f). Coarser plagioclase grains have a weak SPO parallel to the amphibole one.

\subsection{Mineral composition}

The major element compositions of amphibole, plagioclase, and garnet are reported in Table 2 . The amphiboles are classified as pargasite, edenite, or ferropargasite. The plagioclases are oligoclase in 16lzwx2 and 16lzwx3 and andesine in 16lzwx1, \#431-1, and \#431-2, respectively. The garnets are aluminum- and iron-rich. The BSE images and composition profiles from core to rim within single grain show that amphibole and plagioclase grains have approximately homogeneous compositions, without compositional zoning (Figs. S2 and S3). The compositions of contacting amphibole and plagioclase grains are used for the estimation of equilibrium pressure and temperature conditions. The pressure is estimated with the $\mathrm{Al}$ content using an amphibole geothermometer (Johnson and Rutherford, 1989). The temperature is estimated with an amphibole-plagioclase geobarometer (Holland and Blundy, 1994). The estimated equilibrium pressure ( $\sim 1 \pm 0.05 \mathrm{GPa})$ and temperatures $\left(696 \pm 20^{\circ} \mathrm{C}, 630 \pm 18{ }^{\circ} \mathrm{C}\right.$, and $\left.567 \pm 11^{\circ} \mathrm{C}\right)$ of the three EHS samples are similar to those proposed for the retrogression stage (M3) of the EHS garnet amphibolites (Kang et al., 2020). The temperature of 16lzwx3 may be underestimated because the plagioclase was formed by retrogression of garnet. For the amphibole-rich xenoliths, the estimated equilibrium pressures are $1.05 \pm 0.05 \mathrm{GPa}$ in sample \#521, $0.7 \pm 0.05 \mathrm{GPa}$ in sample \#431-1, and $0.54 \pm 0.05 \mathrm{GPa}$ in sample \#4312, respectively. The equilibrium temperatures of \#431-1 and \#431-2 are $612 \pm 9^{\circ} \mathrm{C}$ and $587 \pm 10^{\circ} \mathrm{C}$, respectively. The equilibrium temperature of sample \#521 was not calculated due to the lack of plagioclase.

\section{3. $\mathrm{CPOS}$}

The CPOs of the major constituent minerals were plotted as pole figures presenting orientations of the [100] axes, poles to the (010) 
Table 2

Major element compositions (wt\%) of amphibole, plagioclase, and garnet and equilibrium conditions.

\begin{tabular}{|c|c|c|c|c|c|c|c|c|c|c|c|c|c|}
\hline Sample & Mineral & $\mathrm{SiO}_{2}$ & $\mathrm{TiO}_{2}$ & $\mathrm{Al}_{2} \mathrm{O}_{3}$ & $\mathrm{FeO}$ & $\mathrm{MnO}$ & $\mathrm{MgO}$ & $\mathrm{CaO}$ & $\mathrm{Na}_{2} \mathrm{O}$ & $\mathrm{K}_{2} \mathrm{O}$ & Total & End member & $P \& T$ \\
\hline \multirow[t]{6}{*}{ 16lzwx1 } & Amp & 40.94 & 0.71 & 13.54 & 18.43 & 0.25 & 7.56 & 11.23 & 1.85 & 0.70 & 95.30 & Ferropargasite & $0.99 \pm 0.05 \mathrm{GPa}$ \\
\hline & $1 \sigma$ & 0.32 & 0.08 & 0.10 & 0.33 & 0.03 & 0.06 & 0.06 & 0.11 & 0.01 & & & $696 \pm 20^{\circ} \mathrm{C}$ \\
\hline & $\mathrm{Pl}$ & 57.77 & n.d. & 26.51 & 0.25 & n.d. & n.d. & 8.37 & 6.95 & 0.09 & 99.94 & $\mathrm{Ab}_{60} \mathrm{An}_{40}$ & \\
\hline & $1 \sigma$ & 0.85 & & 0.59 & 0.11 & & & 0.67 & 0.41 & 0.05 & & & \\
\hline & Grt & 37.91 & n.d. & 21.82 & 24.05 & 1.14 & 3.19 & 11.09 & n.d. & n.d. & 99.20 & $\mathrm{Alm}_{61} \mathrm{Grs}_{28} \mathrm{Prp}_{8} \mathrm{Sps}_{3}$ & \\
\hline & $1 \sigma$ & 0.12 & & 0.21 & 0.36 & 0.10 & 0.21 & 0.59 & & & & & \\
\hline \multirow[t]{4}{*}{ 16lzwx2 } & Amp & 44.20 & 0.59 & 14.84 & 15.28 & 0.08 & 10.31 & 9.95 & 2.48 & 0.16 & 97.89 & Pargasite & $1.03 \pm 0.05 \mathrm{GPa}$ \\
\hline & $1 \sigma$ & 0.39 & 0.09 & 0.60 & 0.50 & 0.06 & 0.32 & 0.36 & 0.15 & 0.07 & & & $630 \pm 18^{\circ} \mathrm{C}$ \\
\hline & $\mathrm{Pl}$ & 65.63 & n.d. & 22.44 & 0.02 & n.d. & n.d. & 3.58 & 8.72 & 0.05 & 100.42 & $\mathrm{Ab}_{82} \mathrm{An}_{18}$ & \\
\hline & $1 \sigma$ & 1.11 & & 0.16 & 0.02 & & & 0.26 & 0.44 & 0.01 & & & \\
\hline \multirow[t]{6}{*}{$16 \operatorname{lzwx} 3$} & Amp & 43.65 & 0.42 & 13.82 & 16.27 & 0.07 & 8.95 & 10.63 & 1.97 & 0.52 & 96.43 & Edenite & $0.99 \pm 0.05 \mathrm{GPa}$ \\
\hline & $1 \sigma$ & 0.71 & 0.09 & 0.60 & 0.45 & 0.03 & 0.32 & 0.37 & 0.19 & 0.08 & & & $567 \pm 11^{\circ} \mathrm{C}$ \\
\hline & $\mathrm{Pl}$ & 64.62 & n.d. & 22.18 & 0.07 & n.d. & n.d. & 3.12 & 10.01 & 0.05 & 100.03 & $\mathrm{Ab}_{85} \mathrm{An}_{15}$ & \\
\hline & $1 \sigma$ & 0.26 & & 0.18 & 0.03 & & & 0.20 & 0.16 & 0.02 & & & \\
\hline & Grt & 37.82 & n.d. & 21.83 & 27.27 & 0.94 & 2.75 & 8.53 & n.d. & n.d. & 99.13 & $\mathrm{Alm}_{65} \mathrm{Grs}_{24} \mathrm{Prp}_{8} \mathrm{Sps}_{3}$ & \\
\hline & $1 \sigma$ & 0.09 & & 0.12 & 0.11 & 0.68 & 0.24 & 0.20 & & & & & \\
\hline \multirow[t]{2}{*}{ \#521 } & Amp & 43.32 & 0.33 & 15.11 & 10.79 & 0.16 & 12.79 & 11.33 & 2.41 & 0.38 & 96.62 & Pargasite & $1.05 \pm 0.05 \mathrm{GPa}$ \\
\hline & $1 \sigma$ & 0.54 & 0.05 & 0.47 & 0.33 & 0.03 & 0.28 & 0.16 & 0.07 & 0.04 & & & \\
\hline \multirow[t]{4}{*}{ \#431-1 } & Amp & 45.68 & 0.39 & 10.07 & 13.32 & 0.26 & 12.11 & 12.12 & 1.12 & 1.08 & 96.49 & Edenite & $0.70 \pm 0.05 \mathrm{GPa}$ \\
\hline & $1 \sigma$ & 0.15 & 0.03 & 0.12 & 0.21 & 0.01 & 0.08 & 0.14 & 0.05 & 0.06 & & & $612 \pm 10^{\circ} \mathrm{C}$ \\
\hline & $\mathrm{Pl}$ & 57.31 & n.d. & 26.88 & 0.12 & n.d. & n.d. & 8.80 & 6.61 & 0.13 & 99.86 & $\mathrm{Ab}_{58} \mathrm{An}_{42}$ & \\
\hline & $1 \sigma$ & 0.60 & & 0.39 & 0.04 & & & 0.54 & 0.24 & 0.03 & & & \\
\hline \multirow[t]{4}{*}{ \#431-2 } & Amp & 49.90 & 0.28 & 8.09 & 10.96 & 0.25 & 14.14 & 12.57 & 0.91 & 0.76 & 97.85 & Edenite & $0.54 \pm 0.05 \mathrm{GPa}$ \\
\hline & $1 \sigma$ & 0.16 & 0.02 & 0.08 & 0.22 & 0.01 & 0.09 & 0.06 & 0.02 & 0.08 & & & $587 \pm 11^{\circ} \mathrm{C}$ \\
\hline & $\mathrm{Pl}$ & 57.30 & n.d. & 26.97 & 0.11 & n.d. & n.d. & 8.90 & 6.45 & 0.20 & 99.94 & $\mathrm{Ab}_{56} \mathrm{An}_{44}$ & \\
\hline & $1 \sigma$ & 0.16 & & 0.20 & 0.03 & & & 0.17 & 0.04 & 0.02 & & & \\
\hline
\end{tabular}

P, pressure estimated with the Al content using the amphibole geothermometer of Johnson and Rutherford (1989).

$\mathrm{T}$, temperature estimated with the amp-pl geobarometer of Holland and Blundy (1994).

n.d., not detected.

$1 \sigma$, standard deviation of multiple measurements (5-15 points for each mineral).

Mineral abbreviations: amp, amphibole; pl, plagioclase, grt, garnet; Alm, almandine; Grs, grossular; Prp, pyrope; Sps, spessartine; An, anorthite; Ab, albite.

plane, and the [001] axes for amphibole and the [100] axes, poles to the (010) and (001) planes for plagioclase relative to the structural reference frame (lineation $\mathrm{X}$ and normal to the foliation Z) in Fig. 4.

The CPOs of amphibole are clear in all samples. They are very strong in sample 16lzwx2 and weak in samples \#521, 16lzwx1, and 16lzwx3; the remaining samples show amphibole CPOs of moderate intensity (Fig. 4). The fabric strength ( $J$-index) of amphibole varies from 1.6 to 5.4. Three different CPOs symmetries are observed. The strong amphibole CPOs in sample 16lzwx2 is characterized by an L-type fabric: the [001] axes form a high concentration approximately parallel to lineation and the [100] and the [010] axes form girdles approximately normal to the lineation, with a high concentration of the [100] axes normal to the foliation. Amphibole in samples \#431-1 and \#431-2 has an S-type fabric: the [100] axes form a high concentration approximately normal to foliation and the [010] and the [001] axes form girdles approximately parallel to the foliation. Amphibole in other three samples show weak CPOs with an orthorhombic symmetry, that is an SL-type fabric: the [001] axes forms a maximum parallel to the lineation, with some dispersion in the foliation plane, and the [100] axes have a weak maximum normal to the foliation, with dispersion in the plane normal to the lineation. In samples \#521 and 16lzwx3, a weak maximum of the [010] axes normal to the foliation is also observed.

The CPOs of plagioclase is much weaker than that of amphibole in most samples. It is close to random in samples 16lzwx1 and \#431-2 (Table 3 and Fig. 4). Sample 16lzwx2 has the best-defined plagioclase CPOs characterized by alignment of the [100] maximum subparallel to the lineation and of the [001] maximum normal to the foliation. All samples show a poor concentration of the [001] axes at a high angle to the foliation and of the [100] axes at a low angle to the lineation, respectively. In sample 16lzwx3, the plagioclase CPOs is oblique $\left(\sim 20-25^{\circ}\right)$ to the macroscopic lineation and foliation. In samples 16lzwx1 and \#431-2, the distributions of the [001] and [010] axes are similar while the [100] axes are dispersed in a wide girdle at a low angle to the foliation.
Intracrystalline deformation indicators (GOS map, GOS distribution histograms, and misorientation angle distributions) of the amphiboles in three selected samples (16lzwx2, \#521, and \#431-1) are presented in Fig. 5. The exhumed amphibolite 16lzwx2 has a non-negligible proportion of amphibole grains with high GOS values (grains colored in green to yellow; GOS $>5^{\circ}$, in Fig. 5a), exhibits relatively large frequencies for small misorientation angles $(18 \%$ of the correlated misorientations are $<10^{\circ}$, Fig. $5 \mathrm{~g}$ ). The uncorrelated misorientation angle distribution remarkably deviates from that of a random amphibole CPOs (Fig. 5g), which is consistent with the strong CPOs (Fig. 3b). In contrast, the xenoliths \#521 and, especially, \#431-1 are characterized by lower GOS values, indicating weaker intracrystalline deformation in amphibole (Fig. 5b, c, e, f). The uncorrelated misorientation angle distribution of sample \#521 approximates that of a uniform amphibole CPOs (Fig. 5h), which is consistent with the weak CPOs (Fig. 3a). However, this sample shows a non-negligible proportion of low angle grain boundaries ( $\sim 10 \%$ of the correlated misorientations are $<10^{\circ}$, Fig. $\left.5 \mathrm{~h}\right)$. Despite of the low intragranular deformation, the amphiboles in sample \#431-1 show a clear CPOs (the uncorrelated misorientation angle distribution differs significantly from the one for a uniform CPOs, Fig. 5i). Both xenoliths display a peak at $180^{\circ}$ in the misorientation angle distribution, which indicates twinning, not visible optically, in amphibole.

\subsection{Seismic properties}

The calculated seismic properties are illustrated in Fig. 6. The seismic properties of $100 \%$ amphibole aggregates were calculated using the CPOs measured in each sample. To evaluate the effect of plagioclase on seismic properties of amphibolite, the seismic properties of samples 16lzwx2 and \#431-1, which have high plagioclase contents, were also calculated with various amp/pl ratios (Fig. 7). Variation of the calculated $P$ wave velocity $(V p)$ and the polarization anisotropy of $S$ waves $(A V s)$ as a function of the orientation of the foliation and lineation is displayed in Fig. 8. All seismic data are summarized in Table 3. 


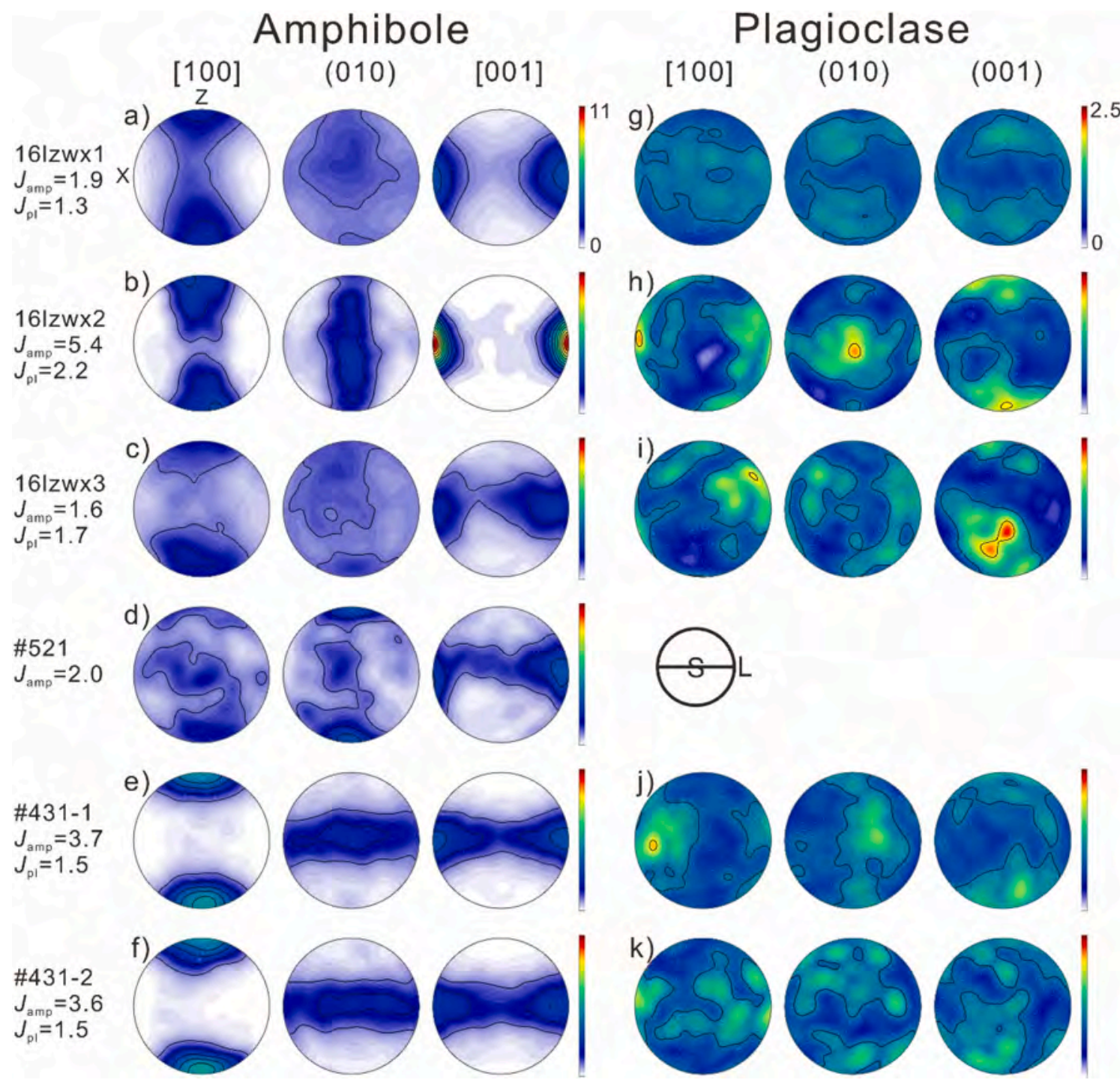

Fig. 4. Crystallographic preferred orientations of amphibole (a-f) and plagioclase ( $\mathrm{g}-\mathrm{k}$ ). Pole figures are plotted as lower hemisphere equal area projections. Color bars (multiples of uniform distribution units) are set as $0-11$ for amphibole, $0-2.5$ for plagioclase. The insert indicates the orientation of the structural reference frame ( $S$ : foliation; $L$ : lineation). $J$-amp: $J$-index of amphibole; $J$-pl: $J$-index of plagioclase. For samples $431-1$, and 431-2, where the lineation could not be identified in the hand sample, the CPOs were rotated to present the maximum [001] of amphibole parallel to the lineation of other samples. For sample 521, where neither the foliation nor the lineation was identified, the CPOs were rotated to present the [001] and (010) maxima of amphibole parallel to the lineation and foliation of other samples, respectively.

The seismic anisotropies vary significantly among the samples, consistent with the variation in strength of the amphibole CPOs. An increase in the plagioclase content decreases both the anisotropies and the velocities of the $P$ - and $S$-waves (Table 3 and Fig. 6). If only the amphibole is considered, the calculated maximum $P$-wave anisotropies $(A V p)$ range between $6.6 \%$ and $17.9 \%$, the maximum $S$-wave polarization anisotropies $(A V s)$ between $4.0 \%$ and $13.9 \%$, the maximum $P$-wave velocities $(V p)$ between 7.3 and $7.8 \mathrm{~km} / \mathrm{s}$, the minimum $V p$ between 6.30 and $6.90 \mathrm{~km} / \mathrm{s}$, the $V p / V s 1$ ratios between 1.62 and 1.84. Sample \#4311 and sample \#521 have the strongest and the weakest seismic anisotropies, respectively.

The seismic property ( $V p, A V s$, and $V s 1$ ) patterns of amphibole are consistent with the amphibole CPOs patterns (Fig. 4), even for samples composed of $50 \%$ amphibole and $50 \%$ plagioclase (Fig. 6). Samples 16lzwx1-3 and \#521 show a similar pattern, which has an orthorhombic symmetry (Fig. 6). The direction of maximum $V p$ is approximately parallel to the lineation (the $[001]_{\mathrm{amp}}$ maximum) and the minimum $V p$ is observed for propagation normal to the foliation (the (100) amp maximum); the strongest $A V s$ is observed for propagation directions approximately normal to the lineation and parallel to the foliation (Fig. 6a-e). Samples \#431-1 and \#431-2 show a different pattern, which has a dominantly hexagonal symmetry with a slow revolution axis; high $V p$ and strong $A V s$ are observed for all propagation directions within or at a low angle to the foliation plane (Fig. 6g-j, Fig. 8a, b). Apparent isotropy or weak anisotropy is observed for $S$ waves propagating normal to the foliation in samples with an S-type or an L- or LS-type amphibole CPOs, respectively. The polarization direction of the fast $S$-wave $(V s 1)$ is parallel to the foliation for $S$ waves propagating within or at a low angle to the foliation in all samples (Fig. 6). Fast polarization directions are parallel to the lineation for all other propagation directions in samples with an L- or LS-type amphibole CPOs (Fig. 6a-f). However, in samples with an S-type amphibole CPOs, the fast polarization directions are at a high angle to the lineation for propagation directions oblique to both the foliation and the lineation (Fig. $6 \mathrm{~g}-\mathrm{j}$ ).

The seismic properties of samples 16lzwx2 and \#431-1 with various amp/pl ratios are shown in Fig. 6b-d \& g-i and Fig. 7. The results show that: 1) The $A V p$ and the maximum $A V s$ decrease progressively with the increase of plagioclase content, indicating that amphibole controls the 
Table 3

Calculated seismic properties of amphibolites using the measured CPOs and different amp/pl ratios.

\begin{tabular}{|c|c|c|c|c|c|c|c|c|c|c|c|c|c|}
\hline Sample & Composition & $\begin{array}{l}A V p \\
(\%)\end{array}$ & $\begin{array}{l}\operatorname{Max} . V p \\
(\mathrm{~km} / \mathrm{s})\end{array}$ & $\begin{array}{l}\text { Min. } \\
V p \\
(\mathrm{~km} / \mathrm{s})\end{array}$ & $\begin{array}{l}\text { Max. } \\
A V s \\
(\%)\end{array}$ & $\begin{array}{l}\text { Max. } \\
\text { AVs1 } \\
(\%)\end{array}$ & $\begin{array}{l}\text { Max. } \\
\text { Vs1 } \\
(\mathrm{km} / \mathrm{s})\end{array}$ & $\begin{array}{l}\text { Min. } \\
\text { Vs1 } \\
(\mathrm{km} / \mathrm{s})\end{array}$ & $\begin{array}{l}\text { Min. } \\
\text { AVs2 } \\
(\%)\end{array}$ & $\begin{array}{l}\text { Max. } \\
\text { Vs2 } \\
(\mathrm{km} / \mathrm{s})\end{array}$ & $\begin{array}{l}\text { Min. } \\
\text { Vs2 } \\
(\mathrm{km} / \mathrm{s})\end{array}$ & $\begin{array}{l}\text { Max. Vp/ } \\
V s 1\end{array}$ & $\begin{array}{l}\text { Min. Vp/ } \\
\text { Vs1 }\end{array}$ \\
\hline 16lzwx1 & $100 \%$ amp & 12.39 & 7.58 & 6.69 & 8.26 & 5.97 & 4.29 & 4.04 & 5.34 & 4.15 & 3.93 & 1.79 & 1.64 \\
\hline \multirow[t]{3}{*}{ 16lzwx2 } & $100 \%$ amp & 15.96 & 7.79 & 6.64 & 9.79 & 6.53 & 4.34 & 4.07 & 7.54 & 4.17 & 3.87 & 1.84 & 1.62 \\
\hline & $\begin{array}{l}75 \% a m p+25 \% \\
\text { pl }\end{array}$ & 13.71 & 7.57 & 6.60 & 9.35 & 6.20 & 4.22 & 3.97 & 6.88 & 4.08 & 3.81 & 1.83 & 1.64 \\
\hline & $\begin{array}{l}50 \% a m p+50 \% \\
\text { pl }\end{array}$ & 11.04 & 7.32 & 6.55 & 8.84 & 5.89 & 4.10 & 3.86 & 6.24 & 3.97 & 3.73 & 1.82 & 1.66 \\
\hline 16lzwx3 & $100 \%$ amp & 8.45 & 7.40 & 6.80 & 5.96 & 4.25 & 4.24 & 4.06 & 3.51 & 4.12 & 3.98 & 1.76 & 1.66 \\
\hline \#521 & $100 \%$ amp & 6.58 & 7.34 & 6.90 & 4.04 & 3.25 & 4.19 & 4.05 & 3.08 & 4.13 & 4.01 & 1.77 & 1.65 \\
\hline \multirow[t]{3}{*}{ \#431-1 } & $100 \% a m p$ & 17.89 & 7.59 & 6.30 & 13.88 & 13.56 & 4.45 & 3.89 & 3.41 & 4.01 & 3.87 & 1.71 & 1.63 \\
\hline & $\begin{array}{l}75 \% \text { amp }+25 \% \\
\mathrm{pl}\end{array}$ & 14.57 & 7.45 & 6.40 & 11.50 & 11.39 & 4.33 & 3.86 & 2.62 & 3.96 & 3.86 & 1.72 & 1.66 \\
\hline & $\begin{array}{l}50 \% a m p+50 \% \\
\text { pl }\end{array}$ & 10.87 & 7.29 & 6.50 & 9.03 & 8.83 & 4.19 & 3.84 & 1.80 & 3.90 & 3.83 & 1.75 & 1.70 \\
\hline \#431-2 & $100 \%$ amp & 17.21 & 7.57 & 6.40 & 13.11 & 12.93 & 4.44 & 3.90 & 3.03 & 4.01 & 3.89 & 1.71 & 1.63 \\
\hline
\end{tabular}

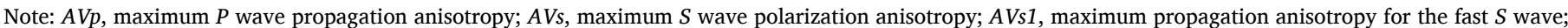

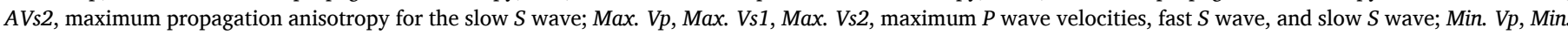
$V s 1, M i n$. Vs2, minimum $P$ wave velocities, fast $S$ wave, and slow $S$ wave.
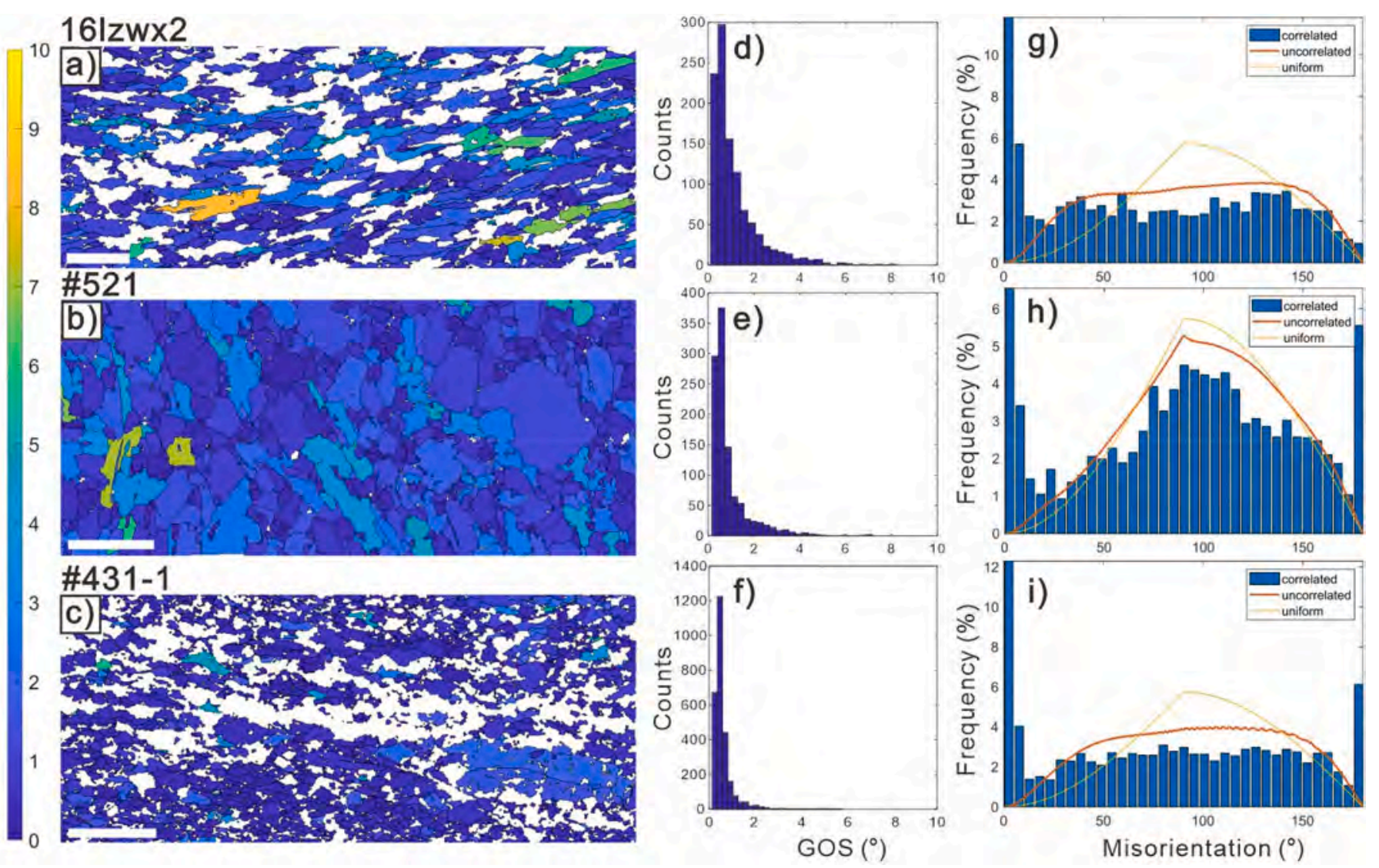

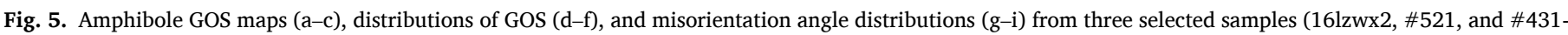

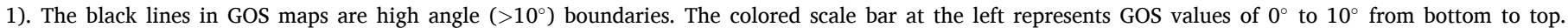

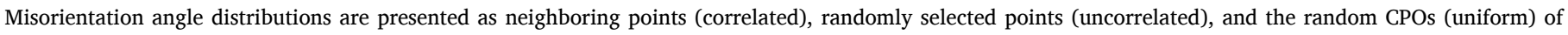

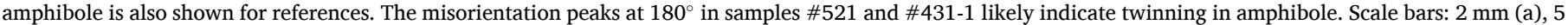
$\mathrm{mm}(\mathrm{b}, \mathrm{c})$.

seismic anisotropy. It is consistent with the stronger anisotropy of the amphiboles and the almost random CPOs of plagioclase in these rocks; 2) The maximum $V p$ and $V s_{1}$ only slightly increase with the increase of amphibole content, suggesting the similar seismic velocities of amphibole and plagioclase.

\section{Discussion}

\subsection{Mechanisms producing the amphibole CPOs}

Amphibole CPOs may form by dislocation creep under hightemperature conditions. In this case, dominant activation of the [001] (100) slip system and secondary activation of the [100](010) and 1/2 


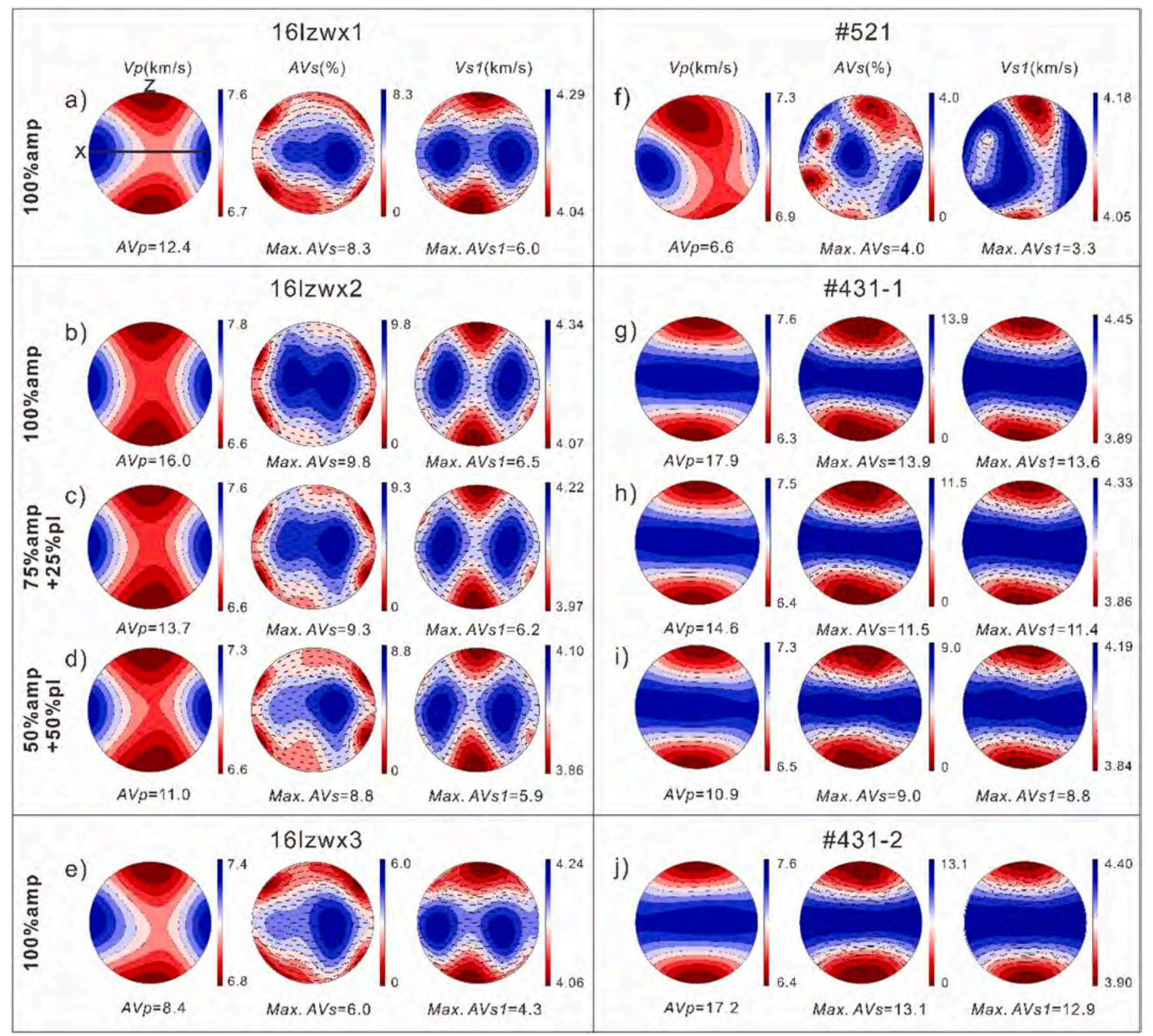

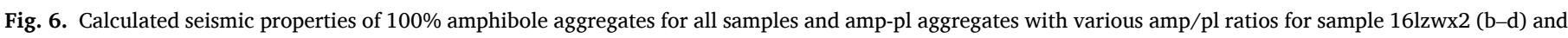

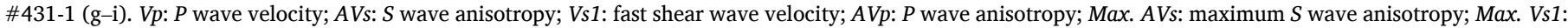

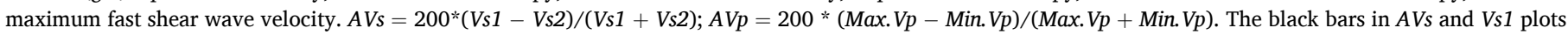
indicate the fast wave polarization directions. The reference frame is the same as in Fig. 4.

$\langle 110\rangle\{110\}$ systems, corroborated by the TEM data (Skrotzki, 1992), produce a strong orientation of the [001] axes parallel to the lineation and the (010) planes parallel to the foliation (Díaz Aspiroz et al., 2007; Elyaszadeh et al., 2018; Skrotzki, 1992). The CPOs of the studied samples could be the result of deformation by dislocation creep. The L or LStype fabrics are associated with simple or pure shear while the S-type fabrics are related to either axial compression or transpressive deformation (Tommasi et al., 1999). Samples 16lzwx1 and 2 show significant intracrystalline misorientation in amphibole (Table 1 and Fig. 5a), consistent with deformation by a dislocation creep. Hence, the bimodal amphibole grain size distribution in sample 16lzwx1 (Fig. 3a) is likely the result of dynamic recrystallization. Recent experimental studies suggest rigid body rotation in fine-grained amphibolite could also contribute to the observed L-type amphibole CPOs (Ko and Jung, 2015; Kim and Jung, 2019). In samples \#431-1 and \#431-2, the low intracrystalline misorientation and well-developed growth twins indicate that amphibole grains were not significantly strained internally. Thus, dislocation creep cannot be the process responsible for the formation of the amphibole CPOs in these samples. Amphiboles in samples \#521 and 16lzwx3 have GOS intermediate values between those of the two groups (Table1) and subhedral shapes (Fig. 2c), indicating that the microstructures and CPOs of these rocks record the activities of more than one process.

Observations of naturally and experimentally deformed amphibolerich rocks indicate indeed that a variety of mechanisms may produce strong CPOs of amphibole, including rigid body rotation by cataclastic flow under low-temperature and high strain rate conditions (Ko and Jung, 2015; Kim and Jung, 2019), diffusion creep in fine-grained aggregates (Getsinger and Hirth, 2014), dissolution-precipitation creep when deformation occurs under melt/fluid-rich conditions (Giuntoli 


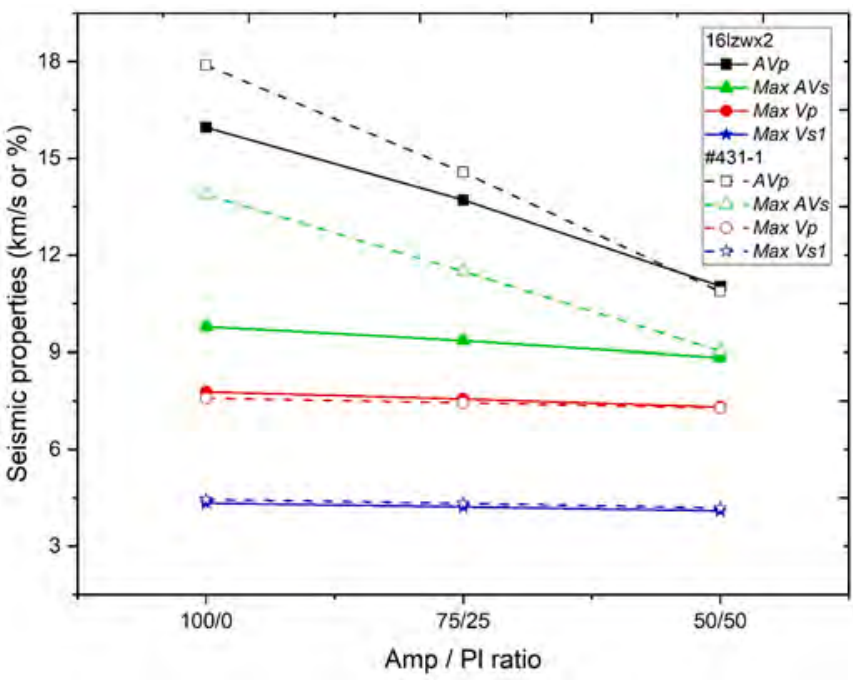

Fig. 7. Relationship between mineral proportion and seismic properties using the CPOs of amphibole and plagioclase in the samples 16lzwx2 and \#431-1.

et al., 2018; Stokes et al., 2012), rotation of non-equant amphibole grains in a deforming magma chamber (Berger and Stünitz, 1996), oriented growth during partial crystallization of low melt fractions in a deforming rock (Tommasi et al., 2017), and topotactic growth during hydration reactions (Padrón-Navarta et al., 2008). All these processes, except topotactic growth, have a common characteristic: they produce correlated amphibole CPOs and SPO (though the SPO may be erased by later textural re-equilibration and does not necessarily develop in the case of metamorphic reactions), but do not involve intracrystalline deformation. However, in magma chambers and fluid-rich settings, compaction may result in the superimposition of small amounts of solidstate deformation in the already crystallized parts of the system, leading to moderate intragranular deformation. Processes involving amphibole growth from fluids or melts may result in compositional zoning if the fluid composition changes during the growth (Giuntoli et al., 2018), but not if the fluid composition remains constant. Given the fact that anisometric growth of amphibole results in prismatic grains elongated parallel to the [001] and flattened parallel to the normal to (100), the CPOs produced by processes depending on the anisotropic grain growth of amphibole bears the same relation to the flow direction and plane as that produced by dislocation creep.

The textures of samples \#431-1, \#431-2, and \#521 suggest that magmatic flow is likely the dominant mechanism for forming the amphibole CPOs. This inference is consistent with the petrological and geochemical data, which indicated that these amphibole-rich xenoliths represent residual cumulates of fractional crystallization of basaltic magma (Xu et al., 2019). In a deforming magma mush, the symmetry of the CPOs will depend on the deformation regime, similarly to CPOs evolution by dislocation creep, but it also depends on the shape of the crystals (Ildefonse et al., 1992). The L- or LS-type fabrics will develop in simple or pure shear (2D flow) for prismatic grains, whereas the S-type fabric will form in axial compressions (such as compaction and transpression) and in pure or simple shear of platy grains. Development of the S-type fabrics as observed in samples \#431-1 and \#431-2 (Fig. 4e, f) may result from either axial compression, a strong component of compression normal to the shear plane, or pure or simple shear affecting platy hornblende grains with a weak elongation parallel to the [001]. The higher GOS values of amphibole in sample \#521 may result from small amounts of solid-state deformation in the already crystallized parts of the system, maybe in response to compaction. Variation in the intensity and symmetry of the amphibole CPOs among the three samples may result from the sampling of different parts of the magma chamber. This interpretation is consistent with the variations in modal composition. The weak CPOs of plagioclase in these samples are coherent with the interstitial shapes of this phase, which implies late crystallization.

Despite the clear SPOs displayed by all three 16lzwx samples, the variation in the intensity of intragranular misorientation in amphibole among the amphibolites from the NBC complex might be explained by added contributions of oriented growth, dissolution-crystallization creep and dislocation creep. Given that these rocks are mafic migmatites (Kang et al., 2020), it is likely that the amphibole CPOs started to develop during the high-pressure granulite facies peak metamorphism (partial melting) and continued to evolve during the retrogression (exhumation). Note that sample 16lzwx2 show the strongest CPOs and SPO and intermediate GOS values in amphibole due to no garnet porphyroblast perturbation to the orientation of the foliation. When present as a major constituent of the rock, as in 16lzwx2, plagioclase shows a weak CPOs, which is consistent with the amphibole CPOs, pointing to a coherent deformation. In samples 16lzwx1 and 16lzwx3, plagioclase is a minor phase mainly occurring around garnet and locally forming pressure shadows (Fig. 3c). It may explain the poor orientation of plagioclase and the obliquity between the plagioclase CPOs and the foliation in sample 16lzwx3.

\subsection{Implication for crustal seismic anisotropy in southern Tibet}

The PmS delay time of the crust is up to $0.8 \mathrm{~s}$ with typical values of 0.45-0.75 s in southern Tibet (Kong et al., 2018; Sun et al., 2015; Sun et al., 2012; Wu et al., 2019; Wu et al., 2015; Zheng et al., 2018). The average delay time of shear wave splitting associated with aligned crackinduced anisotropy in the brittle upper crust $(\sim 15 \mathrm{~km})$ is generally $<0.15$ s (Crampin, 1994). Thus, $2 / 3$ of the Pms delay times measured in southern Tibet are likely generated in the mid-to-lower crust. The delay time is sensitive to both the thickness of the anisotropic layer and the strength of the anisotropy along the propagation direction. The strength of the anisotropy depends on the orientation of the CPOs relative to the propagation direction, which is within $10^{\circ}$ from vertical for the PmS wave (Fig. 8). We have calculated the delay times associated with rocks composed of $100 \%$ amphibole or $50 \%$ amphibole and $50 \%$ plagioclase based on the CPOs data of amphibole and plagioclase in samples 16lzwx2 and \#431-2 using the following equation (Silver, 1996):

$\delta t=\left(A V_{S} / \overline{V_{s}}\right) \times L$

where $\delta t$ is the shear wave delay time, $A V_{S}$ is the anisotropy for the considered propagation direction, $\overline{V_{s}}$ is the shear wave average velocity, and $L$ is the thickness of the anisotropic layer. The maximum anisotropy will be observed if the anisotropic layer in the deep crust has a vertical foliation and a horizontal lineation, that is a strike-slip fabric (dip angle $=90^{\circ}$ in Fig. $8 \mathrm{f}$ ), or a vertical planar fabric (the dip angles for sample \#431-1 in Fig. $8 \mathrm{~b}$ or the dip angle $=90^{\circ}$ in Fig. 8d). In this case, $2 / 3$ of the $P m S$ delay time observed in southern Tibet may be explained by an amphibole-rich ( $\sim 50 \%$ in vol.) layer with a thickness of $14-22 \mathrm{~km}$ (Fig. 9a). Significant delay times are nevertheless produced for all propagation directions at a high angle to the lineation in the case of the LS-type fabrics (Fig. 8b). Propagation directions at a high angle to the foliation result in low delay times in the case of the S-type and the LStype fabrics (a dip angle of $0^{\circ}$ in Fig. 8d or f). The observed delay times cannot be explained by amphibole CPOs associated with flat-lying foliations. Low delay times will also be produced for dipping lineation (the dip angle of $>30^{\circ}$ for sample 16lzwx2 in Fig. 8d).

Seismic radial anisotropy, which describes the discrepancies between the horizontally $\left(V s_{h}\right)$ and vertically $\left(V s_{v}\right)$ polarized shear wave velocities, is typically inferred from observations of a period-dependent discrepancy between the phase or group speeds of Rayleigh and Love waves (Ritzwoller et al., 2002; Shapiro et al., 2004). Strong positive radial anisotropy $\left(V s_{h}>V s_{v}, 4.8 \pm 1.4 \%\right.$ at $25-35 \mathrm{~km}$ depth) was observed in southeastern Tibet below the study area (Fig. 1b), which was 

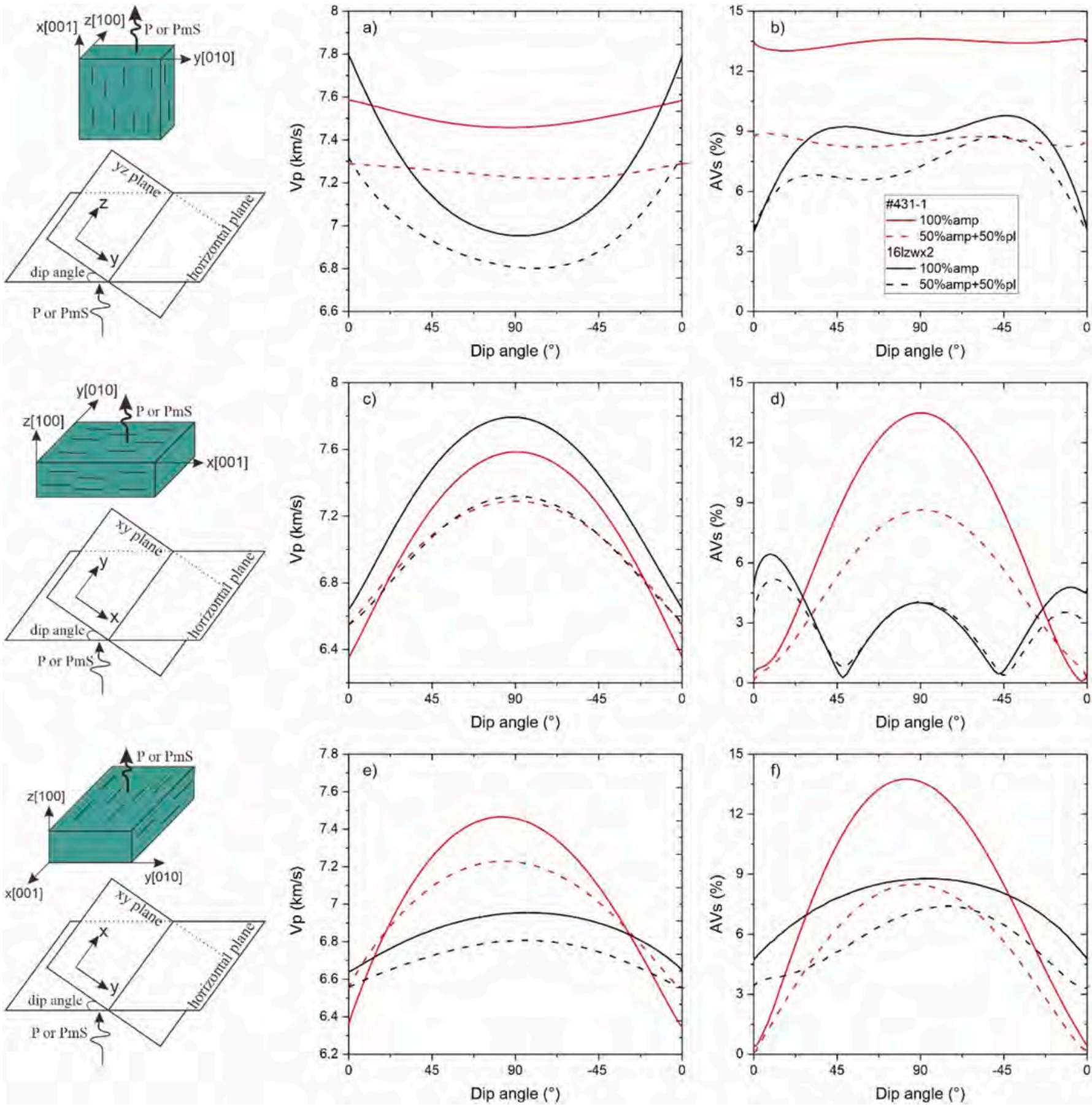

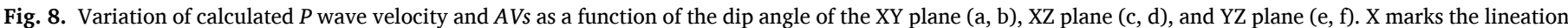
and $\mathrm{Z}$ the normal to the foliation.

interpreted as the result of lateral flow of the Tibetan crust (Agius and Lebedev, 2017; Hu et al., 2020; Shapiro et al., 2004; Xie et al., 2013). Negative radial anisotropy is, in contrast, observed north of the study zone (Hu et al., 2020). The S-type amphibole CPOs can produce strong positive radial anisotropy ( $9 \%$ for amphibolite of $50 \% \mathrm{amp}-50 \% \mathrm{pl}$, Fig. 6i), independent of the propagation direction, when the foliation is subhorizontal. In the case of an LS-type amphibole CPOs, the radial anisotropy would also be positive, but its intensity will depend on the propagation direction (back azimuth), being minimum for propagation parallel to the lineation (Fig. 6d). Vertical foliations will, for both the LSand S-type amphibole CPOs, produce negative radial anisotropy, which will strongly vary as a function of the propagation direction. However, in the case of an LS-type CPOs, if the foliation is vertical and the lineation is horizontal, the radial anisotropy will nevertheless remain low for all back azimuths (Fig. 6d).

In conclusion, the strong crustal anisotropy observed in southern Tibet north of the study zone, using both $P m S$ and surface waves, might be explained by a $15-22 \mathrm{~km}$ thick layer composed of $\geq 50 \%$ vol. of amphibole with an S-type CPOs and a steeply dipping foliation, as in a transpressive shear zone or a synkinematic magmatic body intruding a strike-slip zone. Such a fabric will produce fast $\mathrm{PmS}$ polarization directions parallel to the trend of the foliation. This is consistent with the PmS polarizations mainly parallel to the trend of the multiple dextral strike-slip faults accommodating the lateral escape of southeast Asia east 

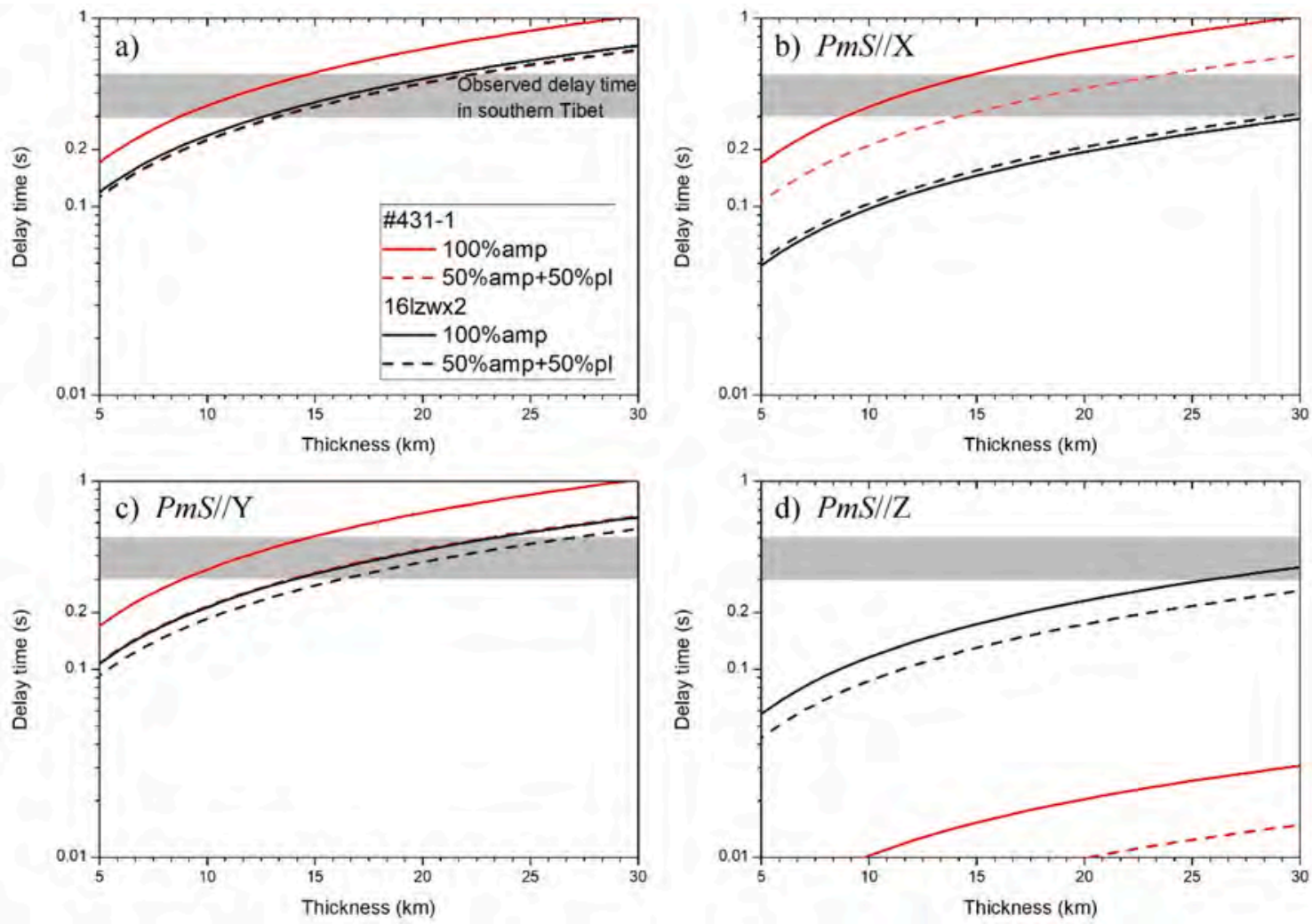

Fig. 9. Relationship between delay time of $S$ wave and thickness of anisotropic layers of $100 \%$ amphibole aggregates and amphibolite composed of $50 \%$ amp and $50 \%$ plagioclase. a) The delay times calculated using the maximum $A V s$ value. b), c), d) The delay times calculated using the AVs values for propagation directions of the PmS parallel to X, Y, and Z, respectively. The shaded area shows the range of delay times observed from the middle-lower crust in southern Tibet. It is assumed that $2 / 3$ of the delay times are contributed by the middle-lower crust.

of the study zone (Fig. 1). However, it is difficult to produce within a single deformed layer both a strong $P m S$ anisotropy and a strong positive radial anisotropy, as the latter requires flat-lying foliations and the polarization anisotropy detected by S-waves propagating normal to the foliation is weak (for the LS-type CPOs, Fig. 6d) to null (for the S-type CPOs, Fig. 8k). A dip-angle variation of the foliation with depth is thus required.

Finally, amphibolites are common rocks, but the volumes needed to explain the observed delay times are significantly larger than those usually observed in the exposed middle to lower crust sections. Locally high $V p / V s$ ratios $(>1.8)$ in the crust of southern Tibet suggest the presence of mafic rocks, but lower values, typical of felsic rocks, predominate (Hu et al., 2020). As a consequence, CPOs of other minerals, in particular micas in the shallower sections of the crust, probably also contributes to the observed anisotropy.

\section{Conclusion}

In this study, the microstructure and seismic properties of amphibole-rich rocks from southern Tibet are presented. These samples display clear amphibole CPOs characterized by pronounced concentrations of the [001] axes parallel to the lineation and the (100) planes parallel to the foliation, respectively. However, the intensity and symmetry of the amphibole CPOs vary between samples, with the L- and LStype fabrics predominating among the samples from the NBC complex and the S-type fabrics among the xenoliths of the Gangdese batholith. Analyses of the microstructures and geochemical data suggest that the amphibole CPOs in the xenoliths formed in response to magmatic flow, whereas those in the NBC amphibolites likely formed by an association of oriented crystallization, dislocation creep, and dissolutionprecipitation creep.
All samples are characterized by strong seismic anisotropies, which tend to decrease with increasing plagioclase content. An amphibole-rich layer $(15-22 \mathrm{~km})$ with a steeply-dipping foliation and an S-type amphibole CPOs might account for both the strong azimuthal PmS anisotropy and the negative radial anisotropy observed to the north and east of the study zone. However, the required amphibolite volumes are too large, indicating that other minerals, in particular micas, probably also contributed to the observed anisotropy. An amphibole-rich layer with horizontal foliation at depths of $35 \mathrm{~km}$ may, on the other hand, explain the strong positive radial anisotropy in southern Tibet. These observations are best explained by the S-type amphibole CPOs, like those observed in the amphibolite xenoliths, which we interpret as produced by the magmatic flow.

The present observations corroborate that strong amphibole CPOs and crustal anisotropy may be formed by a variety of processes, ranging from magmatic deformation to solid-state creep. These different processes produce a similar relation between amphibole CPOs and flow direction and plane. However, in the case of magmatic flow, the S-type fabric may form even in simple shear if the amphibole grains are more flattened than elongated.

\section{Declaration of Competing Interest}

The authors declare that they have no known competing financial interests or personal relationships that could have appeared to influence the work reported in this paper.

\section{Acknowledgments}

We dedicate this article to Prof. Adolphe Nicolas, an exceptional researcher who contribute to our understanding of how deformation 
occurs in the Earth for over 50 years. We are grateful to Fabrice Barou and Wenlong Liu for guidance on EBSD measurement. Deng Xiao is appreciated for help on microprobe analysis. Huizi Jian is thanked for processing seismic data. Pengyuan Han is deeply thanked for sample (\#521, \#431-1, and \#431-2) collection from southern Tibet. Constructive reviews of Dr. Haemyeong Jung, Dr. Loic Labrousse, and editor Dr. Philippe Agard helped us to improve the paper. This work was completed while Xiong Wang was a PhD student at China University of Geosciences (Wuhan) and Université de Montpellier, supported by the National Natural Science Foundation of China (Grants 41425012 and 41590623) and the MOST special fund from the State Key Laboratory of GPMR. This paper was written while Xiong Wang was a postdoctoral fellow at Southern University of Science and Technology, funded by the National Natural Science Foundation of China (Grant 41974098).

\section{Appendix A. Supplementary data}

Supplementary data to this article can be found online at https://doi. org/10.1016/j.tecto.2021.228869.

\section{References}

Agius, M.R., Lebedev, S., 2017. Complex, multilayered azimuthal anisotropy beneath Tibet: evidence for co-existing channel flow and pure-shear crustal thickening. Geophys. J. Int. 210 (3), 1823-1844. https://doi.org/10.1093/gji/ggx266.

Bachmann, F., Hielscher, R., Schaeben, H., 2010. Texture analysis with MTEX - free and open source software toolbox. Solid State Phenom. 160, 63-68. https://doi.org/ 10.4028/www.scientific.net/SSP.160.63.

Bachmann, F., Hielscher, R., Schaeben, H., 2011. Grain detection from 2d and 3d EBSD data-specification of the MTEX algorithm. Ultramicroscopy 111 (12), 1720-1733. https://doi.org/10.1016/j.ultramic.2011.08.002.

Berger, A., Stünitz, H., 1996. Deformation mechanisms and reaction of hornblende: examples from the Bergell tonalite (Central Alps). Tectonophysics 257 (2), 149-174. https://doi.org/10.1016/0040-1951(95)00125-5.

Booth, A.L., Chamberlain, C.P., Kidd, W.S.F., Zeitler, P.K., 2009. Constraints on the metamorphic evolution of the eastern Himalayan syntaxis from geochronologic and petrologic studies of Namche Barwa. Geol. Soc. Am. Bull. 121 (3-4), 385-407. https://doi.org/10.1130/b26041.1.

Boudier, F., Baronnet, A., Mainprice, D., 2010. Serpentine mineral replacements of natural olivine and their seismic implications: oceanic lizardite versus subductionrelated antigorite. J. Petrol. 51 (1-2), 495-512. https://doi.org/10.1093/petrology/ egp049.

Brown, J.M., Abramson, E.H., 2016. Elasticity of calcium and calcium-sodium amphiboles. Phys. Earth Planet. Inter. 261, 161-171. https://doi.org/10.1016/j. pepi.2016.10.010.

Brown, J.M., Angel, R.J., Ross, N.L., 2016. Elasticity of plagioclase feldspars. J. Geophys. Res. Solid Earth 121 (2), 663-675. https://doi.org/10.1002/2015jb012736.

Cai, Y., Wu, J., Fang, L., Wang, W., Yi, S., 2016. Crustal anisotropy and deformation of the southeastern margin of the Tibetan Plateau revealed by Pms splitting. J. Asian Earth Sci. 121, 120-126. https://doi.org/10.1016/j.jseaes.2016.02.005.

Chen, H., Zhu, L., Su, Y., 2016. Low velocity crustal flow and crust-mantle coupling mechanism in Yunnan, SE Tibet, revealed by 3D S-wave velocity and azimuthal anisotropy. Tectonophysics 685, 8-20. https://doi.org/10.1016/j. tecto.2016.07.007.

Crampin, S., 1994. The fracture criticality of crustal rocks. Geophys. J. Int. 118 (2), 428-438. https://doi.org/10.1111/j.1365-246x.1994.tb03974.x.

Davidson, J., Turner, S., Handley, H., Macpherson, C., Dosseto, A., 2007. Amphibole "sponge" in arc crust? Geology 35 (9), 787-790. https://doi.org/10.1130/ G23637A.1.

Díaz Aspiroz, M., Lloyd, G.E., Fernández, C., 2007. Development of lattice preferred orientation in clinoamphiboles deformed under low-pressure metamorphic conditions. A SEM/EBSD study of metabasites from the Aracena metamorphic belt (SW Spain). J. Struct. Geol. 29 (4), 629-645. https://doi.org/10.1016/j. jsg.2006.10.010.

Elyaszadeh, R., Prior, D.J., Sarkarinejad, K., Mansouri, H., 2018. Different slip systems controlling crystallographic preferred orientation and intracrystalline deformation of amphibole in mylonites from the Neyriz mantle diapir, Iran. J. Struct. Geol. 107, 38-52. https://doi.org/10.1016/j.jsg.2017.11.020.

Ferreira, A.M.G., Faccenda, M., Sturgeon, W., Chang, S.-J., Schardong, L., 2019. Ubiquitous lower-mantle anisotropy beneath subduction zones. Nat. Geosci. 12 (4), 301-306. https://doi.org/10.1038/s41561-019-0325-7.

Getsinger, A., Hirth, G., 2014. Amphibole fabric formation during diffusion creep and the rheology of shear zones. Geology 42 (6), 535-538. https://doi.org/10.1130/ G35327.1.

Giuntoli, F., Menegon, L., Warren, C.J., 2018. Replacement reactions and deformation by dissolution and precipitation processes in amphibolites. J. Metamorph. Geol. 36 (9), 1263-1286. https://doi.org/10.1111/jmg.12445.
Hielscher, R., Schaeben, H., 2008. A novel pole figure inversion method: specification of theMTEXalgorithm. J. Appl. Crystallogr. 41 (6), 1024-1037. https://doi.org/ $10.1107 /$ s0021889808030112.

Higgie, K., Tommasi, A., 2012. Feedbacks between deformation and melt distribution in the crust-mantle transition zone of the Oman ophiolite. Earth Planet. Sci. Lett. 359360, 61-72. https://doi.org/10.1016/j.epsl.2012.10.003.

Holland, T., Blundy, J., 1994. Non-ideal interactions in calcic amphiboles and their bearing on amphibole-plagioclase thermometry. Contrib. Mineral. Petrol. 116 (4), 433-447. https://doi.org/10.1007/bf00310910.

Hu, S., Yao, H., Huang, H., 2020. Direct surface wave radial anisotropy tomography in the crust of the Eastern Himalayan Syntaxis. J. Geophys. Res. Solid Earth 125 (5), 1-15. https://doi.org/10.1029/2019JB018257.

Ildefonse, B., Launeau, P., Bouchez, J.-L., Fernandez, A., 1992. Effect of mechanical interactions on the development of shape preferred orientations: a two-dimensional experimental approach. J. Struct. Geol. 14 (1), 73-83. https://doi.org/10.1016/ 0191-8141(92)90146-n.

Imon, R., Okudaira, T., Kanagawa, K., 2004. Development of shape- and lattice-preferred orientations of amphibole grains during initial cataclastic deformation and subsequent deformation by dissolution-precipitation creep in amphibolites from the Ryoke metamorphic belt, SW Japan. J. Struct. Geol. 26 (5), 793-805. https://doi. org $/ 10.1016 /$ j.jsg.2003.09.004.

Ji, S.C., Shao, T.B., Michibayashi, K., Oya, S., Satsukawa, T., Wang, Q., et al., 2015. Magnitude and symmetry of seismic anisotropy in mica- and amphibole-bearing metamorphic rocks and implications for tectonic interpretation of seismic data from the southeast Tibetan plateau †. J. Geophys. Res. Solid Earth 120 (9), 6404-6430. https://doi.org/10.1002/2015JB012209.

Johnson, M.C., Rutherford, M.J., 1989. Experimental calibration of the aluminum-inhornblende geobarometer with application to Long Valley caldera (California) volcanic rocks. Geology 17 (9), 837-841. https://doi.org/10.1130/0091-7613 (1989) 017.

Kang, D., Zhang, Z., Palin, R.M., Tian, Z., Dong, X., 2020. Prolonged partial melting of garnet amphibolite from the Eastern Himalayan Syntaxis: Implications for the tectonic evolution of large hot orogens. J. Geophys. Res. Solid Earth 125 (6). https:// doi.org/10.1029/2019jb019119.

Kawazoe, T., Ohuchi, T., Nishihara, Y., Nishiyama, N., Fujino, K., Irifune, T., 2013. Seismic anisotropy in the mantle transition zone induced by shear deformation of wadsleyite. Phys. Earth Planet. Inter. 216, 91-98. https://doi.org/10.1016/j. pepi.2012.12.005.

Kim, J., Jung, H., 2019. New crystal preferred orientation of amphibole experimentally found in simple shear. Geophys. Res. Lett. 46 (22), 12996-13005. https://doi.org/ $10.1029 / 2019 g 1085189$.

Ko, B., Jung, H., 2015. Crystal preferred orientation of an amphibole experimentally deformed by simple shear. Nat. Commun. 6, 6586. https://doi.org/10.1038/ ncomms7586.

Kong, F., Wu, J., Liu, L., Liu, K.H., Song, J., Li, J., Gao, S.S., 2018. Azimuthal anisotropy and mantle flow underneath the southeastern Tibetan Plateau and northern Indochina Peninsula revealed by shear wave splitting analyses. Tectonophysics 747748, 68-78. https://doi.org/10.1016/j.tecto.2018.09.013.

Kong, F.S., Wu, J., Liu, K.H., Gao, S.S., 2016. Crustal anisotropy and ductile flow beneath the eastern Tibetan Plateau and adjacent areas. Earth Planet. Sci. Lett. 442, 72-79. https://doi.org/10.1016/j.epsl.2016.03.003.

Li, W., Zhang, J., Wang, X., Wang, Y., Wu, X., Hu, Z., 2020. Petrofabrics and seismic properties of Himalayan amphibolites: implications for a thick anisotropic deep crust beneath southern Tibet. J. Geophys. Res. Solid Earth 128 (8). https://doi.org/ 10.1029/2019jb018700.

Liu, H., Niu, F., 2012. Estimating crustal seismic anisotropy with a joint analysis of radial and transverse receiver function data. Geophys. J. Int. 188 (1), 144-164. https://doi. org/10.1111/j.1365-246X.2011.05249.x.

Lloyd, G.E., Butler, R.W.H., Casey, M., Mainprice, D., 2009. Mica, deformation fabrics and the seismic properties of the continental crust. Earth Planet. Sci. Lett. $288(1-2)$, 320-328. https://doi.org/10.1016/j.epsl.2009.09.035.

Mainprice, D., Hielscher, R., Schaeben, H., 2011. Calculating anisotropic physical properties from texture data using the MTEX open-source package. Geol. Soc. Lond., Spec. Publ. 360 (1), 175-192. https://doi.org/10.1144/sp360.10.

Merkel, S., McNamara, A.K., Kubo, A., Speziale, S., Miyagi, L., Meng, Y., et al., 2007. Deformation of $(\mathrm{Mg}, \mathrm{Fe}) \mathrm{SiO}_{3}$ post-perovskite and $\mathrm{D}^{\prime \prime}$ anisotropy. Science 316 (5832), 1729-1732. https://doi.org/10.1126/science.1140609.

Miyazaki, T., Sueyoshi, K., Hiraga, T., 2013. Olivine crystals align during diffusion creep of Earth's upper mantle. Nature 502 (7471), 321-326. https://doi.org/10.1038/ nature 12570.

Nicolas, A., 1992. Kinematics in Magmatic Rocks with special Reference to Gabbros. J. Petrol. 33 (4), 891-915, https://doi.org/10.1093/petrology/33.4.891.

Nicolas, A., Christensen, N.I., 1987. Formation of anisotropy in upper mantle peridotitesa review. In: Composition, Structure and Dynamics of the Lithosphere-asthenosphere System, 16, pp. 111-123. https://doi.org/10.1029/GD016p0111.

Padrón-Navarta, J.A., Garrido, C.J., Sánchez-Navas, A., Tommasi, A., López SánchezVizcaíno, V., Gómez-Pugnaire, M.T., Hussain, S.S., 2008. Oriented growth of garnet by topotactic reactions and epitaxy in high-pressure, mafic garnet granulite formed by dehydration melting of metastable hornblende-gabbronorite (Jijal Complex, Kohistan Complex, north Pakistan). J. Metamorph. Geol. 26 (8), 855-870. https:// doi.org/10.1111/j.1525-1314.2008.00789.x.

Ritzwoller, M.H., Shapiro, N.M., Barmin, M.P., Levshi, A.L., 2002. Global surface wave diffraction tomorgraphy. J. Geophys. Res. Solid Earth 107 (B12), 2335. https://doi. org/10.1029/2002JB001777. 
Shapiro, N.M., Ritzwoller, M.H., Molnar, P., Levin, V., 2004. Thinning and flow of Tibetan crust constrained by seismic anisotropy. Science 305 (5681), 233-236. https://doi.org/10.1126/science.1098276.

Silver, P.G., 1996. Seismic anisotropy beneath the continents: probing the depths of geology. Annu. Rev. Earth Planet. Sci. 24 (1), 385-432. https://doi.org/10.1146/ annurev.earth.24.1.385.

Skrotzki, W., 1992. Defect structure and deformation mechanisms in naturally deformed hornblende. Phys. Status Solidi A 131 (2), 605-624. https://doi.org/10.1002/ pssa. 2211310232.

Stokes, M.R., Wintsch, R.P., Southworth, C.S., 2012. Deformation of amphibolites via dissolution-precipitation creep in the middle and lower crust. J. Metamorph. Geol. 30 (7), 723-737. https://doi.org/10.1111/j.1525-1314.2012.00989.x.

Sun, Y., Niu, F.L., Liu, H.F., Chen, Y.L., Liu, J.X., 2012. Crustal structure and deformation of the SE Tibetan plateau revealed by receiver function data. Earth Planet. Sci. Lett. 349-350, 186-197. https://doi.org/10.1016/j.epsl.2012.07.007.

Sun, Y., Liu, J., Zhou, K., Chen, B., Guo, R., 2015. Crustal structure and deformation under the Longmenshan and its surroundings revealed by receiver function data. Phys. Earth Planet. Inter. 244, 11-22. https://doi.org/10.1016/j.pepi.2015.04.005.

Tatham, D.J., Lloyd, G.E., Butler, R.W.H., Casey, M., 2008. Amphibole and lower crusta seismic properties. Earth Planet. Sci. Lett. 267 (1-2), 118-128. https://doi.org/ 10.1016/j.epsl.2007.11.042.

Tommasi, A., 2004. Strain-induced seismic anisotropy of wadsleyite polycrystals and flow patterns in the mantle transition zone. J. Geophys. Res. Solid Earth 109 (B12). https://doi.org/10.1029/2004jb003158.

Tommasi, A., Tikoff, B., Vauchez, A., 1999. Upper mantle tectonics: three-dimensional deformation, olivine crystallographic fabrics and seismic properties. Earth Planet. Sci. Lett. 168 (1-2), 173-186. https://doi.org/10.1016/s0012-821x(99)00046-1.

Tommasi, A., Langone, A., Padrón-Navarta, J.A., Zanetti, A., Vauchez, A., 2017. Hydrous melts weaken the mantle, crystallization of pargasite and phlogopite does not: Insights from a petrostructural study of the Finero peridotites, southern Alps. Earth Planet. Sci. Lett. 477, 59-72. https://doi.org/10.1016/j.epsl.2017.08.015.

Tommasi, A., Goryaeva, A., Carrez, P., Cordier, P., Mainprice, D., 2018. Deformation, crystal preferred orientations, and seismic anisotropy in the Earth's D" layer. Earth Planet. Sci. Lett. 492, 35-46. https://doi.org/10.1016/j.epsl.2018.03.032.

Vauchez, A., Hollanda, M.H.B.M., Monié, P., Mondou, M., Egydio-Silva, M., 2019. Slow cooling and crystallization of the roots of the Neoproterozoic Araçuaí hot orogen (SE
Brazil): Implications for rheology, strain distribution, and deformation analysis. Tectonophysics 766, 500-518. https://doi.org/10.1016/j.tecto.2019.05.013. Wookey, J., Kendall, J.M., Barruol, G., 2002. Mid-mantle deformation inferred from seismic anisotropy. Nature 415 (6873), 777-780. https://doi.org/10.1038/415777a.

Wu, C., Tian, X., Xu, T., Liang, X., Chen, Y., Taylor, M., et al., 2019. Deformation of crust and upper mantle in Central Tibet caused by the northward subduction and slab tearing of the Indian lithosphere: New evidence based on shear wave splitting measurements. Earth Planet. Sci. Lett. 514, 75-83. https://doi.org/10.1016/j. epsl.2019.02.037.

Wu, J., Zhang, Z., Kong, F., Yang, B.B., Yu, Y., Liu, K.H., Gao, S.S., 2015. Complex seismic anisotropy beneath western Tibet and its geodynamic implications. Earth Planet. Sci. Lett. 413, 167-175. https://doi.org/10.1016/j.epsl.2015.01.002.

Wu, X., Lin, J.F., Kaercher, P., Mao, Z., Liu, J., Wenk, H.R., Prakapenka, V.B., 2017. Seismic anisotropy of the $\mathrm{D}^{\prime \prime}$ layer induced by (001) deformation of post-perovskite. Nat. Commun. 8, 14669. https://doi.org/10.1038/ncomms14669.

Xie, J., Ritzwoller, M.H., Shen, W., Yang, Y., Zheng, Y., Zhou, L., 2013. Crustal radial anisotropy across Eastern Tibet and the Western Yangtze Craton. J. Geophys. Res. Solid Earth 118 (8), 4226-4252. https://doi.org/10.1002/jgrb.50296.

Xu, W., Zhu, D.C., Wang, Q., Weinberg, R.F., Wang, R., Li, S.M., et al., 2019. Constructing the early Mesozoic Gangdese crust in southern Tibet by hornblende-dominated magmatic differentiation. J. Petrol. 60 (3), 515-552. https://doi.org/10.1093/ petrology/egz005.

Yin, A., Harrison, T.M., 2000. Geologic evolution of the Himalayan-Tibetan orogen. Annu. Rev. Earth Planet. Sci. 28 (1), 211-280. https://doi.org/10.1146/annurev. earth.28.1.211.

Zheng, T., Ding, Z., Ning, J., Chang, L., Wang, X., Kong, F., et al., 2018. Crustal azimuthal anisotropy beneath the southeastern Tibetan Plateau and its geodynamic implications. J. Geophys. Res. Solid Earth 123 (11), 9733-9749. https://doi.org/ 10.1029/2018jb015995.

Zhou, J.S., Yang, Z.S., Hou, Z.Q., Wang, Q., 2020. Amphibole-rich cumulate xenoliths in the Zhazhalong intrusive suite, Gangdese arc: Implications for the role of amphibole fractionation during magma evolution. Am. Mineral. 105 (2), 262-275. https://doi. org/10.2138/am-2020-7199.

Zhu, D.C., Wang, Q., Zhao, Z.D., Chung, S.L., Cawood, P.A., Niu, Y., et al., 2015. Magmatic record of India-Asia collision. Sci. Rep. 5, 14289. https://doi.org/ 10.1038/srep14289. 